\title{
12. Color Perception: \\ From Grassmann Codes to a Dual Code for Object and Illumination Colors
}

\author{
Rainer Mausfeld
}

\subsection{Introduction}

Among the many different attributes of visual experiences the attribute of color appears to be the most enigmatic with respect to our attempts to deal with it theoretically. Unlike shape for instance, color does not scem to be part of a physico-geometrical description of the physical worlds. Color rather seems to be a product of the organism's visual system; it appears to be of a subjective nature. Though the concepts of 'subjective' and 'objective' resist any clear-cut definition, it is obvious that color cannot be entirely internal, like emotional states, since under normal conditions color experiences are tied in a lawful way to properties of the physical world. This Janus-facedness of color has not only made color an important target for epistemological inquiries into the relation between the 'external world' and its 'internal representation', but has also made color perception a ficld of paradigmatic interest for investigations into fundamental aspects of the cognitive sciences. Color perception encompasses the entire gamut of levels, from neural transduction to linguistic classifications and conscious percepts, with which the cognitive sciences are concerned.

Its unique blend of physics, neurophysiology and phenomenology makes color science particularly rewarding for studies of foundational and conceptual issues of perception. What propertics does the perceptual coding of physical features of the environment exhibit? What kind of internal structure does the perceptual system impose on the sensory input? How can the achievements of color perception be characterized in terms of the adaptive coupling of the organism to its environment? What kind of physical regularities does the visual system take advantage of in pursuing its functional goals?
Such questions can only be successfully dealt with if one clearly distinguishes different levels of description and analysis: the physical description of perceptually relevant aspects of the physical environment, the phenomenological description, the description of functional achievements and descriptions of neural processing. The notion of a color code, as advanced by Krantz (Suppes et al., 1989 , p. $256 \mathrm{ff}$ ), is a particulary helpful tool for separating these levels in color research and for understanding their interrelation. It allows the conflation of physical, phenomenological and neurophysiological aspects to be avoided and the following questions to be distinguished from one another:

- what kind of psychological relations are referred to? (e.g., metamerism, color cancellation measures, thresholds, color appearances, assessment of 'object colors')

- what is the underlying physical structure? (e.g., physical structure of 'lights', physical structure of 'natural lights' and 'ecological surfaces')

- how can codes with certain properties (e.g., codes for metamerism, codes for unique colors, codes that are illumination independent) be constructed on the basis of the joint psycho-physical structure?

In this chapter I will try to provide an introductory and abbreviated outline of different psychophysical perspectives in color research from a purely psychophysical and functionalist point of view. In order to bring out the basic theoretical elements more clearly I shall, in an intuitive and implicit way, employ the formal notion of a color code and sketch along these lines the Grassmann theory of primary color coding, schemes for opponent color-coding, codes for accounting for spatial and temporal context, and the computational per- 
spective developed in the context of color constancy. This outline then serves as the background for the discussion of some general topics, such as phenomenology and attributes of color, and conceptual problems, like the measurement device conception of color perception. Finally, I shall give the outlines of a new perspective on color perception that is inspired by ethology. According to this perspective, which considers the parsing of the sensory input in terms of, e.g., 'objects', 'surfaces', and 'events' to be determined by an innately fixed categorization process, color is not regarded as simply representing a specific set of physical attributes of the environment, like surface spectral reflectances, but rather is understood as part of the very format, as it were, of the perception instinct that couples our perceptuo-motorial system as a whole to its environment. The celebrated phenomena that show the dialectic relationship of light and object in color perception - which in presentday computational approaches is misrepresented and over-idealized as the "problem of color constancy" - are, according to this view, an inseparable part of our form of perception, rather than a computational achievement of estimating natural surface reflectance functions on the basis of certain sensory inputs. If the perceptual categories of 'illumination color' and 'object color', which are the mold into which the internal coding of color is fitted, are internally constituted by a few 'representative' physical features, then these physical characteristics could be instantiated by an otherwise highly reduced stimulus. Such 'minimal' stimuli would then suffice to trigger internal perceptual achievements, like the segregation of 'object' and 'illumination' information, whose complcxity far exceeds that of the triggering stimulus. Two problems of perceptual theory, though related, have to be distinguished here (referring to two different units of analysis, viz., the individual in a specific context and the evolving species). The first is to understand the nature of the internal 'semantics' of the perceptual categories of 'lights' and 'objects' for a given organism. The second problem refers to evolutionary processes during which the internal semantics originated: what physical properties of the environment gave rise in evolutionary history to the structure of these per- ceptual categories? This second problem is part of a general evolutionary perspective on the universal structure of color perception, as advanced by Shepard (1992; 1994).

\subsection{Elementaristic vs. Ecological Perspectives in Color Research}

In research on color perception we can schematically distinguish two different kinds of theoretical perspectives: an elementaristic psychophysical (and often neurophysiological) perspective focusing on 'front end' color coding, and a functional perspective emphasizing complex pereeptual achievements like color constancy or the perception of shadows or illumination.

The starting points for the elcmentaristic psychophysical perspective are elementary achievements like color matching, color discrimination etc. and their temporal and spatial coding properties. Typical stimuli used here are decontextualized colors, i.e., mere color and light patterns that are not embedded into a natural scene. It is well known that this perspective proved to be fruitful for our understanding of elementary neural color codes.

On the other hand, the functionalist perspective which became intimately connected with a computational approach to color perception takes as its starting point complex achievements of the visual system, like color constancy. The corresponding stimuli are complex 'scenes' that are physically described in terms of complex achievement-related concepts, i.e., in terms of "surface", "specular highlights', 'shadows', 'transparency' etc.

Whereas the elementaristic psychophysical perspective only employs elementary spatio-temporal light patterns as such without relating them to perceptual categories or interpretations in terms of environmental entities, the computational perspective takes the perceptual classification of the environment, i.e., the furniture of the physical world as perceived by the organism, as given and attempts to establish computational mechanisms that allow properties of the theoretically predetermined envi- 
ronment to be reconstructed from the sensory input. In the theoretical language of the elementaristic perspective the stimulus is described in terms of elementary physical variables, whereas the computational approaches tend to describe the input by employing perceptual categories of the output. (The different spirits of these two perspectives is mirrored in the different kinds of apparatus typically employed for experimental investigations, namely Maxwellian viewing systems, as shown in Figure 12.1, vs. complex spatio-temporal patterns on CRT screens.)

Thus, the elementary psychophysical perspective only deals with processes like sensory transduction, filtering, signal-noise analysis etc. without addressing the problem of how elementary perceptual categories, like surface, object and light, are constructed. On the other hand, the computational perspective takes these perceptual categories for granted and uses them right from the beginning for the physical description of the scene. But the physical and the perceptual cate- gories of, say, 'illumination', 'surface', 'object' and 'motion' do not coincide, and the existence of the physical entity is not only not sufficient, but not even necessary for the corresponding percept (think of an object on a CRT screen or in a virtual reality setting). Neither of these perspectives (or combinations thereof) thus deals explicitly with the core problem of how elementary perceptual categories, like 'surface', 'object', 'illumination color' or 'object color' come about. It is this aspect that I shall address in the final section.

Theories on the internal coding of color - both within an elementary and within an ecological perspective - are only weakly and often only very indirectly linked to appearances of color. Yet observations about color appearances usually provide the starting point and motivation for investigations of color coding. Since the question of attributes of color is a far less trivial and settled question than is suggested by the current color term orthodoxy of 'hue', 'brightness' and 'saturation', I shall briefly outline in the next section

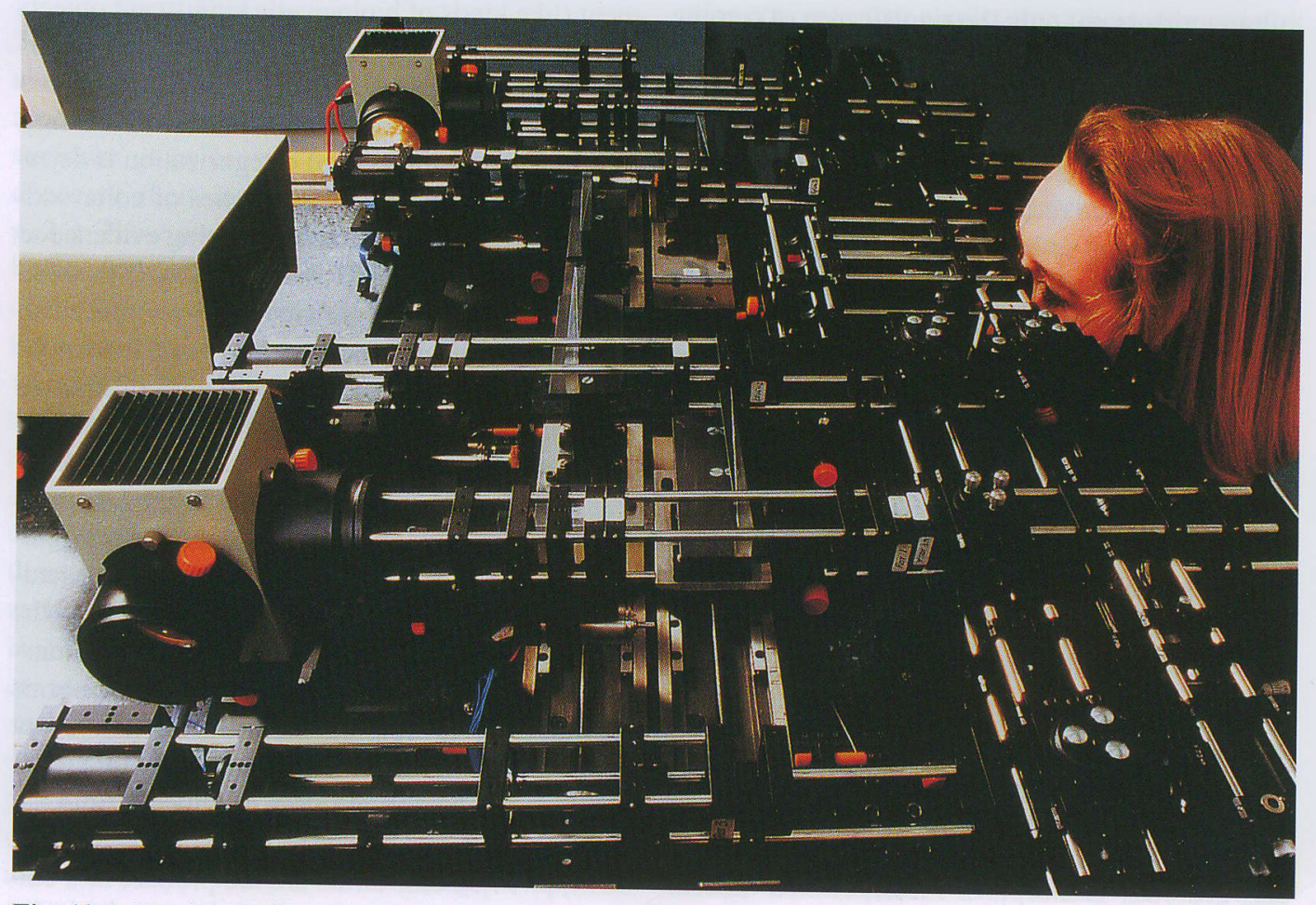

Fig. 12.1: The Kiel micro-optic Maxwellian-view system. 
some of the conceptual intricacies involved in the issues of assessing attributes of color (without dealing with the many empirical intricacies in the complex phenomenology of color appearances).

\subsection{Attributes of Color}

The great variety of nuances of color appearances that natural scenes offer us can only be made accessible for perceptual judgments and linguistic concepts by processes of abstraction and categorization. Color terms gradually emerged in the process of cultural evolution. From Homer's emphasis on forms of light, such as brightness, luster, and the changeability of colors, to the subsequent and continuing interest in the proper color of objects and in color as such, there has been a culturally shaped progression toward an increasingly abstract color vocabulary. Thus, the building-up of a color terminology is a cultural achievement that from the very beginning of human culture mirrors not only the significance of certain biologically important objects, but to an increasing extent the invention and cultural role of coloration techniques and dyeing-processes. Our abstract color terms mostly derive from either concrete objects (like red, which in all Indo-European languages seems to be derived from the Sanskrit word for blood, rudhira, e.g., erythros, ruber, ruadh, rot, rouge, rosso) or from material properties, e.g., shining, glossy, spcckled, dull, drab, resplendent (see Marty, 1879; Hochegger, 1884; Wactzoldt, 1909). Our conscious awareness is of objects and their material character, whereas color appearances only seem to be a kind of medium we are reading through, as it were, in the visual system's attempts to functionally attain the biologically significant object. Therefore cognitive processes of similarity classification and abstractive categorization are necessary for a linguistic description of color experiences. This achicvement of an abstractive categorization entails the Janusfacedness of color with respect to its objective and subjective aspects, mirrored by the incoherence of our everyday concept of color, which hovers bctween two quite different meanings of color, namely (objective) color patches and (subjective) color experiences.

Whereas properties of the brain certainly restrict and predetermine the possible kinds of categorization and linguistic comprehension of pereeptual experiences, there is to date no compelling evidence that the coupling of color experiences to linguistic categories is in a specific way predetermined by properties of internal coding (ef. Frumkina, 1984; for alternative viewpoints see chapter 1 and 11). Though the basic perceptual categories of bright and dark (which have become metaphorically linked to several culturally significant dichotomies) may have influenced linguistic categories, there does not seem to be a fixed set of natural kinds for linguistic color concepts. Biologically and functionally crucial aspects of the perceptuo-motorial system do not map in a natural and direct way to language, but have to be 'reconstructed' by conscious cognitive activity. Our linguistic grip on color experiences is based on a categorization process that is primarily shaped by contingent properties of the environment (like kinds of biologically significant objects and the availability of natural dyes), by the cultural context and the degree of linguistic abstraction achieved. Though there have been several attempts to show that this process of categorization is determined by certain internal propertics of color coding (e.g., Ratliff, 1976), no convincing evidence so far could be provided for such a clam. If the construction of a color terminology is first of all a cultural achievement, it does not come as a surprise that seientific insights into the nature of internal color coding have since the last century themselves reciprocally influenced the way we categorize and classify colors. From the invention of the "basic color attributes" hue, saturation and brightness and the ideas on an internal opponent organization of color to color-order systems, like the Munsell or DIN system (which are used for industrial processes that require standards and norms for referring to colors), the way we talk about color is continuously changing. Therefore it is hardly an exaggeration to say that "'color' did not mean to the Greeks what it means to us" (Irwin. 1974, p. 14). Color terms are the product of a culturally shaped abstraction process. "The Homeric 
Greek had not yet learned to think in abstract terms. 'What is color?' is a question they would never have formulated, let alone been able to answer:" (Irwin, 1974, p. 22)

If we look at standard textbooks on color perception we find the following kind of description of color attributes, which is usually regarded as a natural, unique and complete classification for describing color appearances:

hrightness: "the attribute of a visual sensation according to which a given stimulus appcars to be more or less intense" (Vote the ambiguity of the concept 'intense' in this description.)

huc: "the attribute of a color perception denoted by blue, green, yellow, red, purple, and so on"

saturation: "the attribute of a visual sensation which permits a judgment to be made of the degree to which a chromatic stimulus differs from an achromatic stimulus regardless of their brightness" (Wyszecki and Stiles, 1982, p. 487).

The received, but misguided idea that these attributes adequately characterize color appearances amounts to downplaying the complex phenomenal structure of color expericnces (for linguistic evidence of their inadequacy see Frumkina, 1984, p. 24). These attributes were, in the wake of Helmholtz, derived from the corresponding physical operations of selecting a wavelength, increasing light intensity and diluting a light stimulus with white light. The elementary color attributes were thus taken from elementary physical operations (lurthermore the fact of trichromacy of elementary color coding is incorrectly taken as evidence that color appearances can completely be described by three perceptual variables). Many writers in the early literature were aware of that. For instance, Hering rejected the concept of saturation altogether as a mixing-up of perceptual and physical aspects. He preferred the (reciprocal) concept of veiling ("Verhüllung") of color (Hering, 1920 , p. 40). And Stumpf, who considered the problem of color attributes to be a problem of the ability and the conditions for an isolating abstraction ("Fïhigkeit und Bedingungen der isolierenden
Abstraktion", Stumpf, 1917, p. 8), dismissed 'saturation' as a color attribute completely ("Sättigung können wir nicht als Atribut anerkennen", Stumpf, 1917, p. 86). He conceived saturation to be a cognitive abstraction and a cognitively added relation capturing the approximation of a color to its ideal. In a similar vein, the concept of saturation was rejected by many others, among them Katz and G. E. Müller, who spoke instead of forcefulness ("Eindringlichkeit"), and K. Bühler, who spoke of intensity of colors. Another interesting case is the perceptual category of achromatic appcarances, which being a highly complex - and up to now poorly understood - perceptual achicvement within color perception is from a physicalistic perspective misconceived as a simpler case than color perception proper. Even for achromatic colors, as is well known since Hering, at least a bidimensional account is necessary, as can be witnessed by appearances like luminous grey.

Von Kries, a pupil of Helmholtz, was aware of such problems but he preferred to trade psychological arbitrariness for an apparent precision of color concepts that results from their strong tie to physical operations. He remarked that a division of color appearances in terms of hue, saturation and brightness "does not claim to be a natural one; without much ado we can regard it as a completely arbitrary one. Such a description is, however, a completely rigorous one, since it only refers to objective properties of the light that causes the corresponding appearances" (von Kries, 1882 , p. 6)'.

In the history of perceptual psychology, the physicalistic trap of slicing the nature of perception along the joints of elementary physics is one of the most seductive and misleading ideas. The problematic nature of attempts to parse perceptual phenomena according to categories derived from elementary concepts and operations of physics has

"Diese Gliederung macht keinen Anspruch darauf, eine naturgemässe zu scin; wir können sic vor der Hand als eine ganz. willkürliche betrachten. Sie ist aber cine vollkommen strenge, da sie sich an dic objective Beschaffenheit desjenigen Lichtes hält, welches die betreffende Empfindung hervorzurufen vermag.". 
been discussed since the beginnings of perceptual theory again and again. The conception of the perceptual system as a kind of measuring device which 'informs' the organism about the physical input, along with the idea that elementary physical variables, like intensity and wavelength of light, are connected with elementary perceptual variables, like brightness and color, is an important (mostly implicitly employed) metaphor, which itself is a legacy of the way we separated physical and psychological aspects in the philosophical history of the field and which has governed our thinking in the study of perception since. Along with this measurement device conception of perception (cf., Mausfeld, 1993) comes the idea that there are atoms of perception, as it were, that are strongly tied to these elementary physical variables: namely the sensations from which perceptions - as something referring to the external world -- are constructed.

Because of the difficulties in keeping apart the physical and psychological aspects of the investigation of color and in not succumbing to the stimulus error, Katz (1911, p. 29) remarked: "The most important rule for describing color phenomena is: what vagueness they have needs to be described as such; particularly in this respect there is a dangerous temptation to adulterate the description by perspectives borrowed from physics."'

The problem of how to deal theoretically with the complex phenomenology of color has not been squarely met by current theories of color perception. This is not only testified by the vexing problem of the dimensionality of color codes: Since Hering, Katz, Gelb and others, indications have been accumulating that color appearances cannot be represented by a three-dimensional color code. As Niederée (1996) rigorously showed, even in center-surround configurations the dimensionality of color codes must be greater than three if one is

"Darf ich dic, wic mir scheint, wichtigste Regel für dic Beschreibung von Farbphänomenen nennen, so ist es diese: was an den Farbphänomenen unbestimmt ist, verlangt auch als solches beschrieben zu werden; gerade in dieser Bezichung ist dic Gefahr groß, daß die Beschreibung durch der Physik entlehnte Betrachtungsweisen verfälscht wird." willing to accept the topological assumptions which, at least implicitly, underlie almost all models of color coding. Though this formal argument for the inappropriateness of three-dimensional color codes is based on the traditional view on center-surround stimuli, it is consonant with the perspective to regard center-surround configurations as minimal stimuli for triggering a dual code for 'object' and 'illumination' colors.

\subsection{Early Color Coding and the Elementaristic Approach}

\subsubsection{Newton and Helmholtz's Approach to Color Perception}

Newton regarded color as an intrinsic property of disposition of light alone and he tied the concepts of refrangibility and color together. Newton found the basic fact of what we call metamerism namely that there are lights (i.e., wavelength compositions) that can be physically different but are perceptually indistinguishable - and was awate of the existence of extraspectral hues. He considered (psychologically simple) white light to be physically complex, namely composed of all different lights. One important insight of his is that the ends of the spectrum have something in common perceptually, which led him to provide a metric for specifying color mixtures: his famous center-ofgravity principle. Newton meant this model to be more than just a pictorial representation of his ideas; the model is a quantitative scheme to account for the results of color mixture (and in fact it is the first quantitative model in psychophysics).

Helmholtz started from this model - with some misunderstandings in the beginning that were clarified by Maxwell and Grassmann. Helmholtz's goal was to investigate the nature of (in his words) "terminal processes that are responsible for the dependency of visual experiences on light stimuli." He developed the basic experimental paradigm for investigating basic principles of color perception, connected psychophysical findings with neurophysiological conjectures and provided the fundamentals of a theory of early color coding. 
However, there is one aspect that this theory does not address at all, namely the appearance of color (it only deals with metamerism, i.e., equality of appearances).

\subsubsection{The Young-Helmholtz Theory and Grassmann's Laws}

The Young-Helmholtz theory is based on some simple experimental findings in certain viewing conditions: if a small spot of light - typically of the size of about $2^{\circ}$ visual angle - is presented in an otherwise dark visual field, the psychological relation of metamerism, denoted by $\equiv$, is found to be unaffected by the physical operations of superimposing lights (corresponding to the addition of spectral energy densities), denoted by $\oplus$, and changing intensity of lights, denoted by *.

This means that if $\mathrm{A}$ and $\mathrm{B}$ are perceptually indistinguishable lights (metameric lights), i.e., $\Lambda \equiv B$, with spectral energy distributions $E_{A}(\lambda)$ and $E_{\beta 3}(\lambda)$ and if the same light $C$ with energy distribution $E_{c}(\lambda)$ is added pointwise to each of these lights ( "additive color mixture"), i.c.

$$
E_{\mathrm{A} B \beta}(\lambda)=E_{\Lambda}(\lambda)+E_{B}(\lambda),
$$

then the following relations ("Grassmann laws") hold

$$
\begin{gathered}
\mathrm{A} \oplus \mathrm{C} \equiv \mathrm{B} \oplus \mathrm{C} \\
\mathrm{t} * \mathrm{~A} \equiv \mathrm{t} * \mathrm{~B}
\end{gathered}
$$

Thus, metamerism is (to a large extent) preserved under addition and scalar multiplication of lights.

Together with the trichromacy of color matching and the uniqueness of trichromatic matches, this gives rise to a triple of linear codes that represent metamerism in the following sense. Let $\langle\mathrm{L}, \oplus, *\rangle$ be the qualitative physical structure of lights (where $L$ is the set of lights identified with their spectral radiant energy distributions). Then a mapping $\varphi=\left(\varphi_{1}, \varphi_{2}, \varphi_{3}\right)$ exists which maps the qualitative physical structure $<\mathrm{L}, \oplus, *>$ homomorphically (i.e., linearly) into the thrce-dimensional real vector space, such that $A \equiv B \Leftrightarrow \varphi(A)=\varphi(B)$.

Thus, the physical structure

$$
\langle\text { L. } \oplus, *\rangle
$$

and the psychological structure

$$
<\mathrm{L}, \equiv>
$$

neatly interact to yield the psychophysical structure

$$
<\mathrm{L}, \oplus, *, \equiv>\text {. }
$$

The empirical validity of the Grassmann laws makes the psychological relation a congruence relation with respect to the physical operations (1) and $*$.

The mapping $\varphi$ will be called a Grassmann code. It is not unique, but there exists a whole family of such codes, which are linearly related. Among these are the mappings that represent the physiological receptor codes and the mapping $(\mathrm{X}, \mathrm{Y}, \mathrm{Z})$ that leads to CIE color space.

The visual system thus constructs equivalence classes on the set of physical lights, which from a physical point of view amounts to coarsening the physical description. How perceptual equivalence classes are factored out of the infinite-dimensional physical description is described by the Grassmann laws. These laws make it possible to numerically represent colors in a convex cone in three-dimensional real vector space, which leads to the conception of a three-dimensional color space, whose elements are described by a color code $\varphi=\left(\varphi_{1}, \varphi_{2}, \varphi_{3}\right)$ in this vector space. Classes of metameric lights can then be identified with color appearances.

These Grassmann codes representing metamerism constitute the (purely) psychophysical core of the Newton-Young-Helmholtz theory of color vision (Grassmann, 1853; Schrödinger, 1920; Suppes et al., 1989, ch. 15). As already mentioned above, the notion of a Grassmann code for metamerism does not refer to specific attributes of color (as opposed to color codes referred to in opponent-color theory).

The Grassmann structure of color coding constitutes the core not only of the Young-Helmholtz. theory of color vision but of all other theories of color perception, such as opponent-color theory, industrial systems for specifying color, computational theories of color constancy, etc. Since it is often wedded to tacit additional assumptions and interpretations that go beyond its content, some remarks may be useful. 
1. The Grassmann structure only refers to lights, and not to the color of objects. Though light is the medium for assessing the color of objects, much more complex perceptual mechanisms are involved when the stimulus consists of perceived objects and lights.

2. The only psychological relation involved in the Grassmann structure is metamerism. Therefore only those formal properties of the vector space of equivalence classes of lights can be given an empirical interpretation that are based on the relation of metamerism together with the two physical operations. These are only those that are invariant under linear transformations. Thus the vector space has no cmpirically meaningful scalar product, and Euclidean distances between vectors cannot be interpreted as color similarities or indices of color discriminability. This can be easily seen from the fact that the vector space distance between two colors does not change when the same color is added to both of them; if this third color is, for instance, a very bright one, the psychological distance between the colors will be reduced, however. How to construct a color space in which, in addition to the psychological relation of metamerism, other psychological relations like similarity and discriminability are represented is still an unsolved problem of what Schrödinger called higher color metrics ("höhere Farbmetrik").

3. The idealized and theoretical relation of metamerism - which, for instance, implies strict transitivity of color matches - can only be related to the empirical relation of metameric matches, if (at least implicitly) the usual vector space topology is taken into account. Thus the Grassmann structure needs to be supplemented by topological aspects. Judgmental fluctuations are then taken to lie within a neighbourhood of the 'true' point, and small variations in the physical variables are assumed to lead to small variations in the color appearance (there are no jumps in color appearance). Grassmann (1853, p. 72) and Schrödinger (1920, p. 415 f.) therefore explicitly included continuity assumptions in their formulations.

4. The Grassmann structure does not refer to color appearances (except for the distinguishability-indistinguishability aspect)! In particular, it does not represent equality or inequality of color attributes like hue, saturation, and brightness. The ratio of the length of two vectors does not correspond to a ratio of brightnesses, and a line in Grassmann space does not necessesarily correspond to a constant hue. The Bezold-Brücke shift of hues under changes of intensities of lights does not contradict properties of the Grassmann structure.

5. The well-known nonlinearities of neural coding do not call into question the validity of the linear color representation of the Grassmann theory. First of all, they do not refer only to the Grassmann theory itself (the empirical validity of which is a purely psychophysical question), but to the Grassmann theory cum neurophysiological linking propositions. Secondly, even if the usual linking proposition - discussed below is assumed, namely that two lights are metameric, if they result in the same number of photopigment isomerizations for each of the three univariant types of receptors, any strictly monotonic transformation of this process will preserve the linear representability of the structure.

\subsubsection{Opponent-Color Theory}

Since Leonardo da Vinci and, later, Gocthe, Aubert and Mach 'red' and 'green', and 'blue' and 'ycllow' have been regarded as psychologically basic and principle colors. Gocthe, who considered polarity to be one of the basic principles underlying color experiences (for an account of Goethe's metatheoretical principles on which his approach to color is based, see Mausfeld, 1996) provided central ideas and observations -- notably on afterimages, simultaneous contrast and colored shadows - upon which opponent-color theory came to be based.

For Hering, who took up central principles of Goethe's approach, already the local color code is intrinsically determined by the entire spatio-temporal excitation of the retina. Phenomenologically Hering started from the observation that certain color experiences have the property of being unitary and that pairs of color experiences that cxhibit this property are perceptually incompatible. The 
three perceptual attributes that constitute a distinguished coordinate system for color attributes are the bipolar or opponent pairs: redness/greeness, yellowness/blueness, and whitness/blackness. Hering developed together with a wealth of ingenious experiments - a theoretical account of color coding that was based on such an opponent character of the phenomenal structure of color. His ideas were taken up and further developed by G. F. Müller and others, and more recently by Jameson and Hurvich (see Jameson and Hurvich, 1972), who systematically employed an experimental technique, color cancellation, that was invented by Hering and used by Brückner (1927). The technique of color cancellation allows the detcrmination of the amount of redness in a reddish color by the amount of a standard green that has to be added to bring the color to equilibrium with respect to the redness-grecnness attribute. Thus this technique combines judgments of opponent attributes with the additive structure of the set of lights and allows a version of opponent-color theory to be formulated that refers to configurations consisting only of a single spot of light.

\subsubsection{Color Codes Representing Opponent-Color Attributes}

As a neurophysiological theory, opponent-color theory basically states that the color signals for a homogeneous stimulus emerging from the three types of primary receptors are combined at a second level in some specific way to form three types of channels, denoted here by $Q_{r}, Q_{\mathrm{b}}$ y and $Q_{\mathrm{w}}$, associated with the 'red-green', 'blue-yellow' and 'white-black' opponent color codes, respcctively. This, then, is related to the psychophysical concept of unique colors by means of the linking hypothesis that unique colors are determined by the respective zero points of the two chromatic (neurophysiological) codes. For instance, a 'redgreen equilibrium, i.e., $Q_{\mathrm{rg}}=0$, corresponds to colors that are neither reddish nor greenish, i.e., to either a unique blue, a unique yellow, or a white color appearance. (In addition, positive and negative values of $Q_{r}$ are taken to correspond to color appearances containing a reddish and greenish component, respectively.)
This condition allows the introduction of pairs of chromatic opponent codes $Q_{\mathrm{r} g}$ and $Q_{\mathrm{b}}$ y (using the same notation again) in purely psychophysical terms. The essential qualitative relations involved are (in addition to metamerism and the basic physical attributes) the psychological predicates $\mathrm{U}_{\mathrm{i}}(\mathrm{i}=1,2)$, where $\mathrm{U}_{1}(A), A \in \mathrm{L}$, means the stimulus $A$ being psychophysically in red-green equilibrium, i.c., appearing neither greenish nor reddish, and $\mathrm{U}_{2}(A)$, that $A$ appears neither bluish nor yellowish. The corresponding psychophysical opponent-color theory deals with the qualitative laws governing the interplay of these relations with the relations/operations of the Grassmann structure.

Since the beginnings of opponent-color theory, the meaning of the corresponding types of color codes has undergone various changes, with its interpretation to the present day vacillating between referring to the idea of a 'neural code' vs. a 'psychophysical code', and here in turn between 'perceptual codes' or more abstract ones. Of course, the meaning of such a system of codes may vary with the experimental paradigm and theoretical framework adopted.

\subsubsection{Relating Grassmann and Opponent Codes}

If one considers a system of opponent codes $Q(A)=\left(Q_{\mathrm{r} g}(A), Q_{\mathrm{y}}(A), Q_{\mathrm{w} \mathrm{b}}(A)\right)$ as neural codes, it is natural to ask how they are related to primary receptor codes, i.c., to a Grassmann code $\phi$. A corresponding question can be asked if the opponent codes are considered as purely psychophysical ones (i.c., in terms of qualitative relations and laws conccrning properties of phenomenological relations and their interplay with physical ones). It turns out that from this perspective, triples of opponent codes may simply be chosen among the family of Grassmann codes, provided certain qualitative assumptions in addition to unitariness and incompatibility of attributes - are fulfilled. These conditions have to do with the requirement that cancellation measurements be independent of the choice of the equilibrating light, which imposes the restriction that cancellation equivalences yield one-dimensional Grassmann structures. This 
implies the condition of scalar invariance (of unique colors), i.e., the closure of the class of unique colors under change of intensity. Furthermore, the additive complement of, say, unique green must be unique red, i.e., each unique green can be made achromatic by an addition of unique red.

A corresponding rigorous measurement theoretic analysis of the relation of primary and opponent codes was given by Krantz (see Suppes et al., 1989, chap. 15). This result could also have been stated in such a way that under the above conditions a system of opponent codes can be achieved from a fixed Grassmann code by linear transformations. The operation of color cancellation then yields a linear representation in the vector space derived from the three-dimensional Grassmann structure of metameric color matching, i.e.

$$
\begin{aligned}
& \mathrm{Q}_{\mathrm{rg}}(A)=\Sigma_{\mathrm{i}=1.2 .3} \mathrm{c}_{1,1} \cdot \varphi_{\mathrm{i}}(A) \\
& \mathrm{Q}_{\mathrm{yb}}(A)=\Sigma_{\mathrm{i}=1.2 .3} \mathrm{c}_{2,1} \cdot \varphi_{\mathrm{i}}(A) \\
& \mathrm{Q}_{\mathrm{w}-\mathrm{h}, \mathrm{l}}(A)=\Sigma_{\mathrm{i}=1.2 .3} \mathrm{c}_{3 ., 1} \cdot \varphi_{\mathrm{i}}(A)
\end{aligned}
$$

which, under the above assumptions, neatly connects primary and opponent-color coding (in the experimental situation of a single small light spot in an otherwise dark visual field).

A re-coding of primary color codes into opponent-color channels can be understood as a decorrelation of receptor signals that proves to have interesting formal properties from the perspective of efficient and reliable information transmission in the visual system (Buchsbaum and Gottschalk, 1983).

However, the simplicity and beauty of the exactly defined version of opponent-color theory characterized above is in conflict with empirical evidence. For instance, observations have been reported that

- a mixture of unique green and unique red appears yellowish

- a mixture of unique yellow and unique blue appears reddish

- desaturating a spectral unique blue makes it appear reddish

a unique white is not intensity invariant.

Because of this and other empirical results, the concepts of 'opponent color', 'complementary color', and (successive or simultaneous) 'contrast color' do not coincide. nor do the concepts of 'unique color' and 'intensity invariant color'.

Up to now, attempts to formulate a clear-cut and empirically adequate theory of opponent-color coding have met with little success. There is no coherent and empirically satisfying theory to account for our introspective observations that give rise to the intuition about an opponency of color coding. The field of corresponding research is rather strewn with highly experiment-specific models of opponent coding that are hardly compatible with each other.

There are several other attempts at modelling second or higher-order chromatic mechanisms based not on color cancellation but instead on other kinds of psychological relations, which suggest the existence of a great variety of higher-order color mechanisms. For instance. Krauskopf. Williams and Heeley (1982) investigated changes in chromatic thresholds in chromatically modulated fields and found 'cardinal directions' in color space corresponding to a luminance channel, a red-green channel and an S-cone axis, the last being clearly distinct from the axis defining the set of colors that were in equilibrium for the red-green channel.

\subsubsection{Relating Psychophysical and Neurophysiological Color Codes}

The color codes considered so far are based on only two psychological relations, namely metameric matches and color cancellation (though the motivation that leads to singling out these psychological relations refers to a much richer set of observations). Now the question arises whether the purely psychophysical color codes obtained from color matches and color cancellation techniques can be interpreted in terms of ncural codes. i.c., neural mechanisms.

Current neurophysiological theories of color vision assume two major stages of the primary encoding of color: the first stage refers to the activity of three types of univariant receptors, the second stage to the subsequent integration and reorganization of this activity by cells with spectrally and spatially-opponent response characteristics. 
These two stages of neural encoding are taken to correspond psychophysically (i.e., with respect to psychological relations) to the two types of color codes discussed above. There is, however, a logical gap between quantitative psychophysical notions of color codes that refer only to psychological relations on the one hand, and the ncurophysiological interpretations of these codes in terms of neural codes on the other. Usually, these different interpretations of the term 'code' are simply conflated in vision research parlance. Accordingly, the 'linking propositions' that have to be invoked to bridge this gap are usually not spelled out explicitly.

The linking proposition that has had the greatest appeal in color science since Helmholtz is one that relates the psychophysical code for metameric matches to a corresponding neural code in terms of primary receptors and gives the purely psychophysical concept of metamerism an interpretation in neurophysiological terms based on the idea that among codes for metamerism one can single out certain color codes that in some sense characterize the output of three types of receptors. Psychophysical opponent-color codes are then interpreted as higher order neural codes that result from a certain combination of neural primary codes.

The linking proposition invoked for relating Grassmann codes and primary receptor codes is:

$$
\begin{array}{r}
\mathrm{A} \equiv \mathrm{B} \Leftrightarrow \int \mathrm{E}_{\mathrm{A}}(\lambda) \mathrm{V}_{\mathrm{i}}(\lambda) \mathrm{d} \lambda=\int \mathrm{E}_{\mathrm{B}}(\lambda) \mathrm{V}_{\mathrm{i}}(\lambda) \mathrm{d} \lambda \\
i=1,2,3
\end{array}
$$

where $E_{A}(\lambda)$ is the spectral energy functions of the light $A$, and $V_{i}(\lambda)$ are the spectral sensitivity

\section{Basic color codes in the $2^{\circ}$ paradigm}

\section{Neurophysiological}

Output of three univariant receptor lypes
Psychophysical

Grassmann's laws and trichromacy
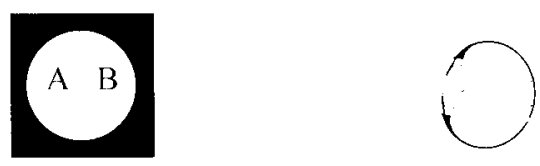

$$
\mathrm{A} \equiv \mathrm{B} \text { metamerism }
$$

neural codes
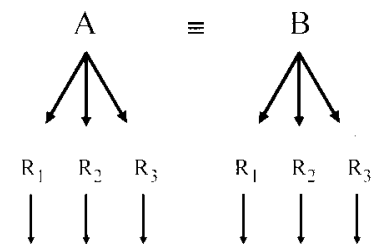

$\int E_{1}(\lambda) V_{i}(\lambda) d \lambda=\int E_{13}(\lambda) V_{i}(\lambda) d \lambda$
Grassmann codes

$$
A \equiv B \quad \Longrightarrow
$$

$$
\begin{aligned}
\varphi(\mathrm{A}) & =\varphi(\mathrm{B}) \\
\varphi(\mathrm{t} \star \mathrm{A}) & =\mathrm{t} \varphi(\mathrm{A}) \\
\varphi(\mathrm{A} \oplus \mathrm{C}) & =\varphi(\mathrm{A})+\varphi(\mathrm{C})
\end{aligned}
$$

Fig. 12.2: Basic color codes. 
distributions for cach of the three types of receptors.

In this way $\varphi_{i}(A)$ can be identified with $\int E_{A}(\lambda) V_{i}(\lambda) d \lambda$, and psychophysical color space is associated with a corresponding three-dimensional sensor space. Figure 12.2 juxtaposes the basic elements of neural and psychophysical color codes in the experimental situation of a small light in an otherwise dark visual field.

Whether this linking proposition is empirically adequate, is still a matter of dispute, since there is conflicting empirical evidence from various sources, notably,

- variability within cone types,

- violations of the persistency rule (metameric lights remain metameric if both viewed in a different context; see below) for women with an additional cone type and for subjects with normal color vision.

Psychophysicists as well as neurophysiologists therefore called into question the validity of a linking proposition as simple as the one stated above. To quote two examples:

“... evidence for the variability among cones is enough to raise serious doubts as to whether trichromatic matches are determined at the receptor level: the cones probably are distinguishing reliably between the matched fields.... it seems to me that we still do not have a satisfactory physiological basis for trichromacy; but we can say that under some conditions at least trichromacy rests on a neural (and not a receptoral) trivariance." (MacLeod, 1986, 109/111)

"Evidence is accumulating to suggest that the idea, that individuals with normal color vision have only three spectrally different cone photoreceptors, is also invalid. ... trichromacy of normal vision has its origin at a level of the visual pathway beyond that of the cone pigments, likely beyond the receptors." (Neitz et al., 1993, p. 122)

Other interesting empirical findings come from experiments with people who exhibit unilateral dichromatism. These rare cases allow dichoptic color matches and comparisons between the two eyes by color-naming techniques that -- under certain assumptions (e.g.. that their color sensations in the dichromatic eye are the same as those of congenital dichromats, and not due to disease) provide insight into the relation between the twoand three-dimensional Grassmann spaces involved and their neurophysiological basis. The experimental study of unilateral dichromatism therefore has been considered of particular interest for our attempts to understand the early coding of color (von Hippcl, 1880; MacLeod and Lennie, 1976: Alpern et al., 1983).

What experimental results can be expected. if there are, for instance, no shortwave receptors (tritanopia) and if thus the input $\varphi_{1}$ is lacking? The Young-Helmholtz theory and standard opponentcolor theory assume that only some of the higher order codes depend on $\varphi_{1}$ and thus that the blueyellow channel $Q_{\mathrm{bg}}$ is missing. According to the standard interpretation of the Young-Helmholtz theory (which links the Grassmann theory with color appearances) one might conjecture that a unilateral tritanopic subject should, with his tritanopic eye, see the spectrum as "red', 'green' and 'yellow' and combinations thereof: neither 'bluc' nor 'white' should be seen, and there should be a green that looks more saturated than any grcen attainable by the normal eye. According to the standard version of opponent-color theory the loss of the 'yellow-blue' channel should result in seeing 'white', 'red' and 'green' as for the normal eye, while the mixture of red and green would be achromatic. Both predictions are in conflict with the experimental results: a unilateral tritanope sees the entire spectrum on the shortwave side of the neutral point between $440 \mathrm{~nm}$ and $550 \mathrm{~nm}-$ as blue, i.e., he matches it to $485-490 \mathrm{~nm}$ in his normal eye. The colors he sees in the spectrum are red, white and blue with only a small amount of yellow and no green at all. Thus it seems that central elements in the linking propositions of the Young-Helmholtz theory and opponent-color theory are utterly wrong:

"those central mechanisms which. in the normal observer, correspond to blueness fand we assume, have heavy dependence on the output of the short-wave cones) are most active indeed in the tritanope." (Alpern et al., 1983, p. 694)

This and other results support the conjecture that the psychophysically observed threc-dimensionality of color matches in the $2^{\circ}$-paradigm cannot be 
attributed in a simple way to the existence of three types of photoreceptors:

"There must be a limitation to only three degrees of freedom at the level of central mechanisms, not merely at the level of photopigments." (Alpern et al., 1983, p. 693)

Whereas a neurophysiological perspective on color deals with the neural architecture of the visual system and the minutiae of the neural coding of color, psycho-physics deals with the interplay of phenomenology and physics and with abstract "strategies" that the visual system employs for achieving its tasks, without cmbarking on speculations about neural mechanisms. To reveal the underlying strategies is first and foremost a psychological or psychophysical task, since only when we have an idea of the basic 'logic' of the system can we speculate on neurophysiological implementation (which may pertain to a unit of analysis other than the level of neurons). Though there is not and cannot be a sharp boundary between psychophysical and neurophysiological work, differences in emphasis and orientation with respect to these two levels of analysis can be discerned.

Attempts to understand the relation between psychophysical codes and the neurophysiology of color coding have since the beginnings of color research been the driving forces in the field. For the psychology of color perception this situation is not without problems, since psychology faces in its history the danger of a centrifugal tendency by which certain sub-fields spin away into other disciplines. This is certainly the case with large areas of color science. Here, psychology has not yet taken on its due role and to a large extent has relinquished a field of genuine psychological interest to neurophysiology. The tendency that perceptual psychologists notoriously avail themselves of neurophysiological terms when it suits their "explanatory" purposes and hastily call upon ad hoc pseudo-explanations for isolated psychophysical phenomena in terms of equally isolated neurophysiological findings is testimony to the higher 'epistemological dignity' they ascribe to neurophysiology. However, given the complexity now apparent both in psychophysical observations and in neurophysiological findings, claims that empir- ical results provide sufficient constraints to bridge the logical gap between the two levels of description seem to be based on forlorn hopes. In the light of what little is presently understood of the physics of the brain, neuroreductionism amounts to no more than a bold speculation about what might be the relevant aspects. Even worse, it rests on a misconstrued account of the development of scientific theories which almost always was due to explanatory unification rather than reduction.

\subsubsection{Elementary Color Codes Accounting for Variations in Spatial and Temporal Context}

So far I have only referred to experimental situations where the stimulus is a small spatially and temporally homogeneous light in an otherwise dark visual field (typically experimentally studied under so-called Maxwellian viewing conditions, shown in Figure 12.1, where the subject's head is fixed and a beam of light is projected through the pupil on the retina). Though it is assumed that the Grassmann laws and qualitative laws of color cancellation are valid over a wide range of spatial and temporal contexts, the color appearances themselves can change with variations of context. It therefore appears natural to try to accommodate the effects of context in theories of early color coding.

Several theoretical perspectives have been developed to account for spatial and temporal effects; these perspectives are intimately tied to certain phenomena and corresponding paradigmatic experimental situations; the terms 'adaptation', 'induction' and 'contrast' can - in an idealized manner - be associated with specific experimental stimulus situations. However, evaluation of the many experiments investigating spatial and temporal aspects of color perception is impeded by the poorly understood effects of the details of the experimental situations (which often involve complex interactions of spatial and temporal aspects as well as different judgmental criteria and viewing conditions). This abundant variety of different experimental setups and stimulus conditions mirrors the theoretical uncertainty about how to carve the multitude of phenomena into those 
which are considered as 'basic' and those which are considered as side-effects.

The Young-Maxwell-Helmholtz-Grassmann theory describes the transduction of light into a psychophysical or neural code and - together with the linking proposition proposes a receptoral mechanism that accounts for the Grassmann laws. Since metamerism is the only psychological relation involved, the theory does not refer to color appearances. However, color appearances are often tacitly associated with the equivalence classes of metameric lights. In this case the theory becomes a locally-atomistic account of color appearances. It then has to deal with the problem that at one location of a visual scene the same triple of Grassmann codes/receptor outputs can give rise to quite different color appearances if the temporal or spatial context is varied. The existence of a surround changes the color appearances in characteristic ways and produces new appearances, e.g., brown, that cannot be observed in a dark surround (see chapter 10).

From a locally-atomistic perspective these are secondary effects, to be treated under the heading of 'context' effects. On the other hand, they could also show that the basic mechanisms determining color appearances in natural scenes can only be tapped by 'minimal stimuli' that are richer than the $2^{\circ}$ lights appropriate for isolating receptoral transduction.

For the elementaristic perspective on color perception (as opposed to a functional one guided by ecological physics) the effects of certain temporal and spatial variations on the local color appearance were considered an important challenge. To a surprising extent, the Young-Helmholtz tradition, however, was successful in developing an extension of the theory that could - at least in principle - incorporate an important class of these effects.

The first systematic investigations into mechanisms responsible for these variations were performed by Fechner (1840). The complementary character of afterimages led Fechner to the idea of a tiring of physiological processes (based on an analogy with a "loss of tension" - "Verlust an Spannkraft") by which "all phenomena concerning afterimages and adaptation can be reduced to sensitivity processes in the eye" Fechner, 1840, p. 430) $)^{3}$ This intuition lead Helmholt $\angle$ to his concept of "fatigue of receptors" ( "Ermüdungstheorie"), which was given a more precise form by von Kries" "coefficient scheme" ("Koeffizic'ntensutz").

Because the Young-Helmholt 2 theory took as basic units of analysis single light spots in a dark surround, it had to postulate additional mechanisms to account for the effects of spatial and temporal context. For opponent-color theory on the other hand it was more natural to incorporate spatial and temporal effects, since its underlying intuitions were historically rooted in phenomena that depend on variations of temporal and spatial contexts (Hering attributed a much more basic role to contrast and adaptation than Helmholt/ did). To theoretically deal with the situation of a single isolated light in a dark surround only became possible after the invention of the color cancellation technique which according to Brückner (1927) was already used by Hering.

In the following sections, I shall briefly outline how the Young-Helmholtz theory and a variant of opponent-color theory deal with temporal and spatial contexts in terms of appropriate codes (or code transformations).

\subsubsection{The von Kries Coefficient Scheme}

Helmholtz took up Fechner's intuitions and conjectured that "the fatiguing of the organ of vision modifies the sensation of the just-sensed light approximately in a way as if the objective intensity of the light is reduced to a certain fraction of its magnitude." (Helmholtz, 1911, Vol. 2, p. 200)t.

This perspective allows any effects of adaptation to be translated back to physics and to describe them as if only the effective physical stimulus had changed.

"durch die man dic ganze Erschcinung der Nachbilder auf ein Spiel von Empfindlichlicit des Auges reduciren kann"

4 “... die Ermüdung der Sehnervensubstany die Empfindung neu einfallenden Lichtes ungefaihr in dem Verhältnis beeinträchtigt, als wäre dic objcktive Intensität dieses Lichtes um einen bestimmten Bruchteil ihrer Größe vermindert." 
An explicit model of this intuition to account for the effects of temporal adaptation was first proposed by von Kries (1882). Based on the hypothesis of linear sensitivity control acting on three types of primary receptors, this so-called von Kries coefficient scheme assumed that the effect of adaptation can, for each receptor type, (approximately) be described as multiplication of each receptor code by a real number.

Adaptation is regarded here as a differential fatiguing of the three types of receptors. The sensitivity of each type of receptor is assumed to be reduced over the spectrum by a constant factor, i.e., the spectral sensitivity curves change their amplitude but not their form, i.e.

$$
V_{i}^{\prime}(\lambda)=\rho_{i} \cdot V_{i}(\lambda) \quad \rho_{i} \in(0,1)
$$

Three numbers $\rho_{1}, \rho_{2}, \rho_{3}$ thus suffice to completely describe the process of adaptation.

Though it was originally intended to be a newrophysiological hypothesis ("fatigue of receptors"), many of the corresponding empirical investigations address its psychophysical counterparts.

To formulate its psychophysical counterpart, I shall use the notation of Mausfeld and Niederée (1993) for the characterization of the stimuli employed: two stimuli $\mathrm{A}$ and $\mathrm{B}$ that are presented after pre-adapting by a light $S$, will be writen as $\angle \mathrm{A}, \mathrm{S}\rangle$ and $\langle\mathrm{B}, \mathrm{S}\rangle$. More generally, I shall use this notation for any temporal or spatial context $S$. Two such stimuli $\langle\mathrm{A}, \mathrm{S}\rangle$ and $\langle\mathrm{B}, \mathrm{T}\rangle$ which have the property that the testficlds A and B look 'the same color" will be called isophene:

$$
\langle\mathrm{A}, \mathrm{S}\rangle \equiv\langle\mathrm{B}, \mathrm{T}\rangle \text {. }
$$

For the case of a dark surround $(\mathrm{S}, \mathrm{T}=\mathbf{0}$, where $\mathbf{0}$ is the zero energy distribution) the concepts of metamerism and isophenism coincide, i.e., $\mathrm{A} \equiv \mathrm{B}$ can be identified with $\langle\mathrm{A}, \mathbf{0}\rangle \equiv\langle\mathrm{B}, \mathbf{0}\rangle$.

Now, if the linking proposition that characterizes the Young-Helmholtz theory, namely

$$
A \equiv B \Leftrightarrow \int E_{\lambda}(\lambda) V_{i}(\lambda) d \lambda=\int E_{F}(\lambda) V_{i}(\lambda) d \lambda
$$

is valid for the dark-adapted eye, then the von Kries coefficient scheme amounts to the validity of the following linking proposition for the eye pre-adapted by some light $\mathrm{S}$ :

$$
\begin{aligned}
<\mathrm{A}, \mathrm{S}>\equiv<\mathrm{B}, \mathrm{S}>\Leftrightarrow \int \mathrm{E}_{\Lambda}(\lambda) \rho_{\mathrm{i}}(\mathrm{S}) \cdot \mathrm{V}_{\mathrm{i}}(\lambda) \mathrm{d} \lambda & \\
=\int \mathrm{E}_{\mathrm{B}}(\lambda) \rho_{\mathrm{i}}(\mathrm{S}) \cdot \mathrm{V}_{\mathrm{i}}(\lambda) \mathrm{d} \lambda & \\
& \quad i=1,2,3
\end{aligned}
$$

where $\left(\rho_{i}\right.$ is a function of $\varphi(S)$ (or of $\varphi_{i}(S)$ if it is assumed to be independent of the two remaining channels). In terms of primary receptor codes this means that the effect of context $S$ on the color appearance of a testfield $A$ can be completely captured by a transformation $\varphi_{i}(A) \rightarrow \rho_{i}(\varphi(S)) \cdot \varphi_{i}(A)$.

The right equation directly shows the symmetry of the operations 'reducing receptor sensitivity by a factor' and 'reducing the effective intensity of light for this receptor by the same factor' (though there is not necessarily a physically realizable light that fulfills this symmetry condition for all three receptor types simultaneously).

From this linking proposition a number of important psychophysical consequences follow: Metameric classes of lights must be preserved under adaptation ("Persistenzsatz", persistency rule):

$\mathrm{A} \equiv \mathrm{B} \Rightarrow\langle\mathrm{A}, \mathrm{S}>\equiv\langle\mathrm{B}, \mathrm{S}\rangle$

for any pre-adapting light $S$

Furthermore, the Grassmann linearity laws must remain valid for any constant state of adaptation of the eye. This must be true also for the case of asvmmetric adaptation (e.g., both eyes adapted differently, matches between both eyes):

$$
\begin{aligned}
& <\mathrm{A}, \mathrm{S}\rangle \equiv<\mathrm{B}, \mathrm{T}\rangle \text { and }<\mathrm{C}, \mathrm{S}\rangle \equiv\langle\mathrm{D}, \mathrm{T}\rangle \\
& \Rightarrow<\mathrm{A} \oplus \mathrm{C}, \mathrm{S}>\equiv<\mathrm{B} \oplus \mathrm{D}, \mathrm{T}\rangle
\end{aligned}
$$

and

$$
\begin{aligned}
& <\mathrm{A}, \mathrm{S}>\equiv<\mathrm{B}, \mathrm{T}> \\
& \Rightarrow<\mathrm{t} * \mathrm{~A}, \mathrm{~S}>\equiv<\mathrm{t} * \mathrm{~B}, \mathrm{~T}>\text { proportionality rule } \\
& \text { ("Proportionalitätssatz") }
\end{aligned}
$$

The transition from one state of adaptation to another can, according to this theory, be described by a linear transformation of the corresponding tristimulus values, i.e., by a $3 \times 3$ matrix $M$. With respect to the spectral sensitivity functions of the cones this transformation is completely described by three numbers, i.e., a diagonal matrix D. Von Kries already was aware of the fact that the validity 
of these laws provides another possibility for estimating the cone spectral sensitivities by transforming the $3 \times 3$ matrix $\mathrm{M}$ by $\mathrm{B}^{-1} \mathrm{MB}$ into a diagonal matrix D of reals (daß "die Ermüdungsversuche die Möglichkeit zu einer directen Bestimmung der Componenten bieten", von Kries, 1882, p. 108).

The von Kries coefficient scheme is at the core of many approaches for dealing with mechanisms of sensitivity control, adaptation and color constancy in psychophysics, neurophysiology ("multiplicative gain control') and computational vision. In fact, 'the' psychophysical von Kries hypothesis as well as the proportionality rule split up into a variety of different hypotheses dependent on the experimental and theoretical paradigm chosen. Von Kries' original ideas of including adaptational phenomena within the Young-Helmholtz theory primarily refer to aspects of temporal adaptation ('successive contrast'), whereas the use of von Kries type transformations in computational approaches to color perception primarily refers to effects of spatial contexts that mirror changes in the prevailing illumination (a typical example is to interpret the transformation $\varphi_{i}(A)\left(\varphi_{i}(\rho(S)) \cdot \varphi_{i}(A)\right.$ as a kind of normalization of the receptor codes corresponding to a surface A under some illumination by the receptor codes of a white surface under the same illumination).

Various psychophysical investigations into the von Kries hypothesis have been carried out since, with more or less negative results (cf. Wyszecki and Stiles, 1982, p. 429 ff.). Many of the relevant experimental studies have concentrated on consequences of the von Kries hypothesis rather than on the hypothesis itself, notably the linearity laws (Wyszecki and Stiles, 1982, p. 431) and among these the proportionality rule. This rule has, under several experimental paradigms, been shown to fail (cf. Jameson and Hurvich, 1972). There is abundant evidence both in psychophysics and neurophysiology that there are many types and sites of adaptation in the visual system (cf. MacLeod, 1978; Walraven and Valeton, 1984; Walraven et al., 1990). For instance, Ahn and MacLeod (1993) found that chromatic adaptation had different effects on flicker photometry and unique yellow settings.
Even in cases where a multiplicative von Krics transformation is suggested by the data, the coefficients might not be easily identifiable with a certain stage of neural processing, since a single coefficient can comprise the effects of many transformations at quite different stages. Nevertheless. the failure of 'the' von Krics law/proportionality rule gave rise to search for 'additional mechanisms' (in an attempt to preserve the basic spirit of a linear coefficient law), notably 'subtractive' ones.

\subsubsection{The "Two-Process Interpretation" of Spatial and Temporal Effects in Opponent-Color Theory}

The effects on color appearance of spatial and temporal variations of context were at the origin of opponent-color theory. Hering focused on certain spatial interactions of colors and corresponding phenomena traditionally subsumed under the headings 'light induction', 'color induction". 'simultaneous contrast' etc. These phenomena offer a natural starting point for a spatially oriented relational point of view as advanced by Fechner, Mach, Hering, Katz, Bühler, Koffka, and Land, to mention only a few well-known names. According to this perspective, color is inherently determined by features of the entire visual scene. Both aspects, the preadaptational and the relational one, are often couched in the same language of adaptation, and it is, in fact, often difficult to tell them apart in experimental or theoretical work.

Within the framework of opponent-color theory an explicit mathematical model to account for the effects of adaptation and induction in terms of opponent-color processing was proposed by Jameson and Hurvich (e.g., 1972). This is the socalled "two-process interpretation", whose mathematical core is a formal scheme, which, like the von Kries coefficient scheme, allows for different interpretations.

Whereas the linear version of opponent-color theory discussed in section 12.4 .3 refers to a single spot of light only, the "two-process interpretation" also refers to the effect of a (spatial) context in which a test light is seen and yields an affine version of opponent-color theory. When applied to a system $\varphi$ of linear primary codes, the model can. 
for the 'red-green system', be given the following schematic form:

$$
Q_{r-\underline{s}}(\mathrm{~A} ; \mathrm{S})=\sum_{1.2,3} \mathrm{k}_{i}(\mathrm{~S}) \cdot \varphi_{\mathrm{i}}(\mathrm{A})-I(\mathrm{~S})
$$

where A denotes the presented lights and $\mathrm{S}$ the (spatially or temporally) adapting light, and $\mathrm{k}_{\mathrm{i}}(\mathrm{S})$ and $I(S)$ are real numbers. The Jameson-Hurvich model postulated analogous equations for the other two channels.

This model is different from the linear opponent-color model of section 12.4.3.2. that was based on color-cancellation experiments. Whereas, under suitable linearity assumptions, the opponent codes derived from color-cancellation experiments with a single homogeneous spot of light belong to the class of Grassmann codes, the opponent codes of the Jameson-Hurvich model are affine functions of the linear primary codes and are, thus, not Grassmann codes themselves.

There are several important variants of this model like Walraven's (1976) "discounting the background" model:

$$
Q_{1-13}(A ; S)=\Sigma_{i=1.2 .3} k_{i}(S) \cdot\left(\varphi_{i}(A)-\varphi_{i}(S)\right)
$$

This model assumes that in stimuli of the kind $\mathrm{A}=\mathrm{S} \oplus \Delta$ only the incremental part $\Delta$ is subjected to a von Kries type sensitivity control:

$$
Q_{1 .}(\Delta ; S)=\sum_{\mathrm{i}=1.2,3} \mathrm{k}_{\mathrm{i}}(\mathrm{S}) \cdot \varphi_{\mathrm{i}}(\Delta) .
$$

A discussion of these models can be found in Mausfeld and Niederée (1991; 1993).

In the next section I shall summarize a theoretical scheme for color codes in center-surround stimuli, put forward by Mausfeld and Niederée (1993), that is based on a contrast code of primary receptor signals and incorporates both multiplicative and subtractive mechanisms of sensitivity control. This scheme, called the Octant Model (because it partitions the receptor excitation space into eight regions), on the one hand allows a simple interpretation in traditional terms of front end contrast coding. On the other hand, theoretical as well as empirical observations connected with it lead in a natural way to a more sophisticated reading of this model in terms of complex perceptual achievements. I shall turn to the corresponding functionalist and ethology-inspired perspective in section 12.6 .

\subsubsection{The Octant Model and Increment-Decrement Asymmetry}

There is ample evidence in color research supporting the idea that spatio-temporal transients provide the essential 'information' for the coding of color. The following model is based on corresponding theoretical ideas and empirical results and tries to specify some basic aspects of such a transientbased perspective for a 'minimal' kind of stimulus configuration that suits a relational transientbased perspective of color, according to which, at each point, color is determined by the relation between (at least) two 'lights', characterized by their spectral compositions, one pertaining to this very point and the other(s) to its neighborhood.

As above, I shall denote a stimulus consisting of a central infield $A$ presented in a surround/background $S$ (each characterized by the primary color codes $\left.\varphi_{i}(\mathrm{~A}), \varphi_{\mathrm{i}}(\mathrm{S}), \mathrm{i}=1,2,3\right)$ by $\langle\mathrm{A}, \mathrm{S}\rangle$. (In the following I use the terms 'surround' and 'background' interchangably, A, B, ... always denote the absolute infields.)

Consider two such stimuli $<\mathrm{A}, \mathrm{S}>$ and $<\mathrm{B}, \mathrm{T}>$. Of course, if the two infields $A$ and $B$ have identical values with respect to a Grassmann code $\varphi$ and if the two surrounds $S$ and $T$ also have identical $\varphi$ values, the two stimuli are isophene:

$$
\begin{aligned}
& \text { If } \varphi(A)=\varphi(B) \text { and } \varphi(S)=\varphi(T), \\
& \text { then }\langle A, S\rangle \equiv\langle B, T>\text {. }
\end{aligned}
$$

The converse, however, is not true, since different vectors in six-dimensional real vector space may result in isophene infields. Therefore, many attempts in color science have been made to find a color code $\Phi$ that captures the appearance of the infield, i.e.

$$
<\mathrm{A}, \mathrm{S}>\equiv<\mathrm{B}, \mathrm{T}>\Leftrightarrow \Phi(\mathrm{A}, \mathrm{S})=\Phi(\mathrm{B}, \mathrm{T}) .
$$

and that is some simple function $h$ of the corresponding Grassmann code. More precisely, one wants to find some vector valued function on the six-dimensional real vector space such that $\Phi(A, S)=h(\varphi(A), \varphi(S))$ is a color code for the appearance of the infield.

Examples for $h$ are linear functions in the infield for a fixed surround (e.g., von Kries, Land) and 
affine functions (e.g., Jameson and Hurvich, Walraven, Shevell, Larimer) that take values in the three-dimensional real vector space.

The Octant Model is an incrementally linear model consonant with several empirical and theoretical findings on color coding. It assumes a contrast code $\Phi_{i}$ for each channel $i$ and predicts that between the infields of two such configurations a color match is obtained if the respective contrast codes for the two stimuli coincide (interestingly enough, neurophysiological as well as psychophysical observations suggest that the primary signals in the retina result from contrast coding, whereas absolute brightness and color must be approximately reconstructed by higher-order processes). The contrast code $\Phi_{i}$ is given by the difference $\phi_{i}(A)-\phi_{i}(S)$, which in turn is subjected to a multiplicative surround-dependent transformation $\rho_{i=}[S]$ (or, more precisely, $\rho_{i+}[\varphi(S)]$ ). The distinctive feature of the Octant Model is that these transformations are allowed to be different for increments (i.e., $\left.\phi_{i}(A)-\phi_{i}(S) \geq 0\right)$ and decrements (i.e., $\left.\phi_{\mathrm{i}}(\mathrm{A})-\phi_{\mathrm{i}}(\mathrm{S})<0\right): \rho_{\mathrm{i}+}[\mathrm{S}] \neq \rho_{\mathrm{i}-[}[\mathrm{S}]$. In neurophysiological terms, the sign of the response in each of the three color channels depends entirely on the background, and the 'ON' and 'OFF' parts of each channel are subjected to different multiplicative gain controls. The result that incremental and decremental stimuli are processed differently does not come as a surprise in view of both the phenomenological distinction between aperture and surface modes of color perception, and the functionalist distinction between illumination colors and object colors.

All incrementally linear models that assume that incremental and decremental stimuli were subjected to the same multiplicative surround-dependent transformation $\rho_{\mathrm{i}}[\mathrm{S}]$ imply a qualitative law of increment-decrement symmetry: let $\Delta$ be an increment supcrimposed on a background $\mathrm{S}$ and $\Delta^{\prime}$ another increment on a background $\mathrm{T}$ such that the two infields are isophene (i.c., $\langle\mathrm{S} \oplus \Delta, \mathrm{S}\rangle$ $\equiv<\mathrm{T} \oplus \Delta^{\prime}, \mathrm{T}>$ ); then the infields of the corresponding decremental stimuli (if they are physically realizable) must also be isophene (i.e., $<\mathrm{S} \ominus \Delta, \mathrm{S}\rangle \equiv\left\langle\mathrm{T} \ominus \Delta^{\prime}, \mathrm{T}\right\rangle$ ). If, on the other hand, the principle of increment-decrement symmetry is violated for a certain viewing condition and judg- mental mode, then for such a condition no incrementally linear model with $\rho_{i}[\mathrm{~S}]=\rho_{i}[\mathrm{~S}]$ can hold.

A simple phenomenon, called hminumc' 'ontrast phenomenon (Niederée and Mausfeld, 1996). already qualitatively shows that increment-decrement symmetry cannot hold generally. Furthermore, quantitative experiments of ours show that the multiplicative "gain control" coefficients differ indeed considerably for increments and decrements (Mausfeld and Niederéc, 1992). This difference does not only show up between proper increments and proper decrements, but between several octant boundaries: Heyer (1996) by explicitly extending the Octant model to a subsequent stage of opponent coding - was able to show experimentally 'kinks' of unique bluc lines in unique yellow surrounds at several octant boundaries.

The difference in processing between increments and decrements (or, more generally, the coding properties described by the Octant Model) could possibly be understood as resulting from the structure of the elementary perceptual categories of 'object color' and 'illumination color', which will be addressed below.

The above presentation confined itself to the abstract core of basic elementary color codes. The elementaristic perspective on color coding is. however, much more variegated and richer and incorporates for instance mechanisms related to eye-movements, filling-in processes, contrast coding etc. Nevertheless, there are many phenomena that cannot be easily accommodated in the clementaristic perspective on color coding (cf. Mausfeld and Niederée, 1993, sec. 9) and necessitate an additional and different approach to color perception.

\subsection{Ecological and Computational Perspectives}

The elementaristic perspective on color coding proved to be immensely fruitful for our understanding of the primary transduction and neurophysiology of early color coding. The elementaris- 
tic perspective is. however, ill-equipped to deal with problems of color perception in complex scenes. This does not mean that there are simply some lacunae to be filled in the future in the theoretical picture the elementaristic perspective draws of color perception. Rather the entire perspective is, in a pernicious way, misleading if one attempts to extend it to problems of color perception in natural scenes.

It goes without saying that this does not challenge the fact that the Grassmann theory constitutes the basis for any theory of complex color coding. In particular, almost all approaches to color perception assume that the pattern of color appearances which is evoked by a spatio-temporal array of lights $A_{j}$ is a function of the corresponding tristimulus array $\varphi\left(A_{j}\right)$. This assumption, called extended primary trichromacy by Mausfeld and Niederee (1993), is equivalent to the assumption that the pattern of color appearances does not change if each light $A_{j}$ is replaced by a metameric light.

When an elementaristic perspective on color vision attempts to incorporate functionalist aspects of goals of perception it succumbs to a measurement device (mis-)conception of perception. This may be exemplified by Barlow's (1982, p. 635) remark that "For color vision, the task of the ele is to discriminate different distributions of chergy oler the spectrum." In a similar vein Buchsbaum and Gottschalk (1983, p. 92) state: "The visual sistem is concerned with estimating the spectral functional shape of the incoming color stimulus."

The success of the elementaristic approach to color vision with respect to neurophysiological concerns has for many decades reduced psychophysics to an auxiliary discipline of neurophysiology. Corresponding attitudes have prevailed in psychophysics and veiled the fact that since the beginning of scientific investigations into color perception an alternative perspective has been developed that takes into account functionalist aspects of perception and starts from the idea that color perception deals with complex perceptual achievements in connection with the interplay of light and objects. This perspective had already been clearly expressed by Hering (1920, p. 13):
"Vision is not a matter of perceiving light rays as such, but the ability to see external objects by means of these rays; the eye's task is not to inform us about the respective intensity or quality of the light that comes from the external objects, but to inform us about the objects themselves."

Hering's commitment to a functionalist perspective has since then been echoed and advanced by Bühler, Heider, Brunswik, Gibson, Shepard, to mention just a few well-known names. Unfortunately, the prevailing orthodoxies of elementaristic and neurophysiologically oriented psychophysics suppressed complex functionalist approaches to color perception to such an extent that it took quite some time and effort to once more attain the level of insights that one can find in the classic literature, e.g., in Gelb (1929) or Kardos (1935). These insights have been resurrected in a new guise due to the emergence of artificial intelligence research, where they have inspired various computational approaches to color vision.

We can schematically distinguish two kinds of approaches to theoretically deal with the internal coding of the color of objects under varying illuminations. The adaptational perspective emphasizes the role of simple elementary mechanisms that neutralize the effects of changes of the illumination. Of these the most prominent is a von Kries-type normalization of the receptor output by an illumination-dependent factor. Such an adaptive rescaling could in principle yield a good approximation to color constancy if reflectance and illuminant spectra are broad relative to the bandwidth of the receptors. The basic spirit of an adaptational perspective on color constancy can already be found in Hering, who considered color constancy as primarily due to elementary and primitive processing modes of the visual system.

\footnotetext{
"Nicht um das Schauen der Strahlungen als solcher handelt es sich beim Sehen, sondern um das durch diese Strahlungen vermittelte Schauen der Außendinge; das Auge hat uns nicht über die jeweilige Intensität oder Qualität des von den Außendingen kommenden Lichtes, sondern über diese Dinge selbst zu unterrichten."
} 
Explicit accounts from different theoretical perspectives were given by Ives (1912) and Jaensch (1914) who introduce the concept of level, and later, among others, by Helson, Judd, Land, Brill and West (e.g., West and Brill, 1982), MacLeod (1986), and Foster and Nascimento (1994).

Non-adaptational approaches to color constancy were developed by Sällström, Buchsbaum, Brill, Maloney and Wandell, and D'Zmura and Iverson. These approaches are explicitly couched in terms of the computational goal of recovering from the sensory input a function that depends only on certain physical properties of objects, viz. characteristics of surface reflectance.

In the following I shall very briefly sketch some of the basic ideas of the adaptational and nonadaptational approaches using the example of Land's Retinex scheme and of Maloney's algorithm which is based on the linear framework approach.

\subsubsection{The Problem of Approximate Color Constancy from a Computational Point of View}

A strong locally-atomistic perspective on color perception takes the color appearance at each location $k$ of the visual field to be determined by the light pertaining to this very location. i.c.. by the respective triple $\varphi\left(A_{k}\right)$ alone. This alleged pointto-point correlation of wavclength composition and color appearance is in conflict with many empirical phenomena, among them colored sladows and the phenomenon that colors of objects tend to remain fairly constant under changes of the color of the illumination.

The formal core of the problem of color constancy as viewed from a computational perspective is schematically shown in Figure 12.3. The variables involved are the spectral energy distribution $E(\lambda)$ of the illumination and the spectral $r$ flectance function $\mathrm{R}(x, \lambda)$ at a location $x$ of a surface. The signal coming to the eye is the point-wise product of illumination and reflectance, as it were. It causes in each type $i$ of photoreceptors a ncural signal. In this signal the illumination component and the reflectance component are completely confounded. Nevertheless, the internal representation. i.c., the percept of the (approximately) 'true' color of the surface, requires a kind of disentangling of the two components. On the basis of local information of a single position $x$ this is of course. impossible, on logical grounds (analogously to the impossibility of identifying each of the factors for a given product of two numbers). Visual mechanisms that accomplish a (largely) illuminationindependent perceptual assessment of the color of
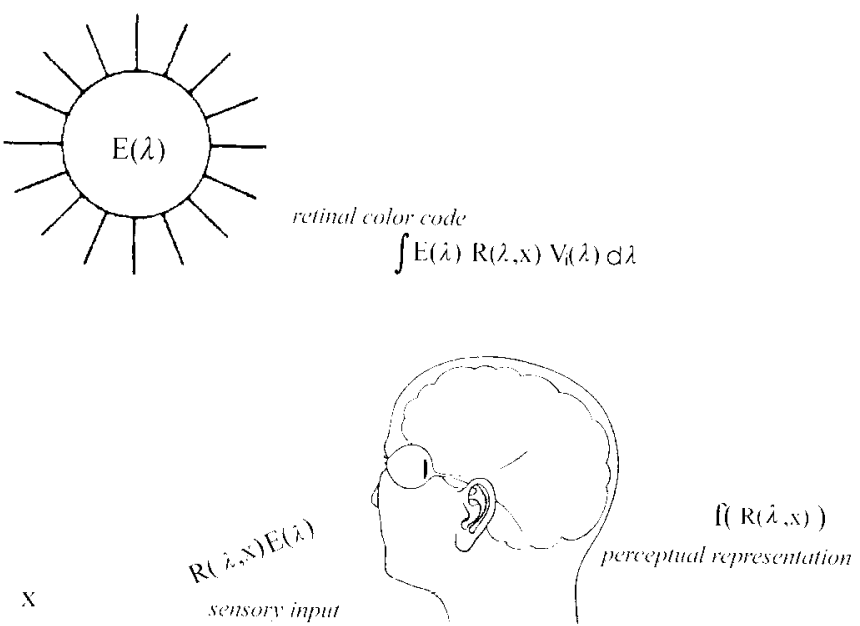

$\mathrm{R}(\dot{\lambda}, \mathrm{x})$

Fig. 12.3: The problem of color constancy. 
objects must consequently be based on some global operations of the visual scene.

\subsubsection{Land's Approach to Color Constancy}

Investigations into the problem of color constancy underwent a revival due to the ingenious 'Mondrian' demonstrations of Edwin Land. To account for his findings Land put forward several versions of a simple computational scheme, which he called Retinex Theory. This scheme was motivated by the idea that the illuminant has to be completely discounted. Land's approach was to find color designators (i.e., a triple of numbers) for which the following hold:

i) designators are invariant under changes of illumination (for a fixed configuration of surfaces)

ii) equal designators correspond to identical color appearances.

Whereas i) is a requirement from a computational perspective, ii) ties the illumination-invariant code to perceptual relations; it assumes perfect color constancy (within one fixed scene).

In Retinex theory these color designators are obtained by a simple comparison and normalization procedure. For a given test field $x$ of a fixed Mondrian that is illuminated homogeneously, the procedure can, in terms of Grassmann color codes, be described as follows: Let $\varphi_{、}=\left(\varphi_{1 . x}, \varphi_{2, x}, \varphi_{3, x}\right)$ be the value of the Grassmann code of the light coming from $x$. Correspondingly, let $\varphi_{y}$ for all other patches y of the Mondrian denote the respective (irassmann codes. The (later version of the) Retinex algorithm basically calculates the geometric mean $G(\varphi$,$) and normalizes the color code of$ the test field with respect to this geometric mean, i.c. $\varphi, G\left(\varphi_{3}\right)$. This color code $\mathrm{L}=\varphi_{\mathrm{x}} / G\left(\varphi_{\mathrm{y}}\right)$ is (under strong assumptions about lights and surfaces) invariant over changes in illumination if the average spectral reflectance of the Mondrian considered corresponds to a mid-grey reflectance.

It is obvious that the Retinex algorithm is formally equivalent to a von Kries-type transformation. where the coefficients $\rho_{\mathrm{i}}$ are assumed to be inversely proportional to the geometric mean of the Grassmann codes of the Mondrian areas.
Land's computational approach to color constancy, despite being theoretically unsatisfactory and at variance with cmpirical observations, stimulated further theoretical and empirical research on color constancy immensely.

Scveral other adaptational algorithms for color constancy have been developed that are also based on a von Kries-type normalization and assume that there is either a white surface available in the scene or that the average reflectance of the scene is a mid-grey. Foster and Nascimento (1994) provided evidence that illuminant invariant codes may be achieved by a direct coding of spatial color relations, since cone excitation ratios are for natural surfaces almost invariant under changes in natural illuminants. Forsyth (1990) proposed for a Mondrian world a framework for extracting illuminant information hidden in the gamut of Grassmann codes for all possible surface reflectances under some illuminant.

\subsubsection{The Linear Model's Framework and Maloney's Algorithm}

The most prominent class of non-adaptational models of color constancy are based on the following idea: analyses of large sets of empirical surfaces and lights as wcll as investigations into the physical processes that determine surface spectral reflectances have led to the conjecture that the spectral energy distributions of 'natural' lights and many surface spectral reflectance functions are well approximated by a linear combination of a fixed finite set of frequency-limited basis functions. Each surface spectral reflectance is then expressed as a lincar combination of $n$ basis functions. The number $n$ and each of the $n$ basis functions is assumed fixed and to be independent of the surfaces considered, the weights of this linear combination can vary to generate all possible surface reflectances for this particular linear model. The residual error is remarkably small, since, for instance, eight basis functions account for over 0.99 of overall variance for large sets of natural spectral reflectances.

Based on such a finite-dimensional linear physical model for the underlying physical variables a model that is only weakly constrained by per- 
ceptual considerations - Maloney (1985, 1992) proposed a mechanism that exploits the underlying physical regularities. Its goal is to estimate from the sensory input a function that depends only on the surface spectral reflectance function. For his algorithm, Maloney assumes that for the case of three receptor types each light can be sufficiently well approximated by a linear combination of three basic lights, and each surface reflectance by a linear combination of two basic reflectance functions, i.e., the vector space of permissible lights has the dimension 3 , the vector space of permissible reflectances the dimension 2 . Therefore the values of the Grassmann codes of the permissible reflectances under a fixed permissible light come to lie in a two-dimensional linear subspace of the three-dimensional Grassmann space. Maloney provided natural assumptions under which this subspace is characteristic for the illumination in the sense that the illumination can - up to scalar multiplication - be determined from the position of this subspace with respect to the Grassmann space. This in turn allows the determination - up to scalar multiplication - of the reflectances. For a set of empirical reflectances the system would have to determine (according to some distance measure) the best approximating linear subspace in sensor space (if one chooses the Euclidean distance this task is accomplished by some kind of principle component analysis).

Maloney's penetrating analyses into the mathematical structure that results from the interaction of lights, surfaces and properties of the eyc (together with assumptions of the visual system's task) can be considered an important accomplishment for the conceptual clarification of the problem of color constancy. On empirical grounds, however, the general assumption that the visual systems's achievement is to obtain a function of the sensory input that depends on $\mathrm{R}(x, \lambda)$, but not on $\mathrm{E}(\lambda)$, which on Maloney's account is tantamount to recovering reflectances, does not seem to be appropriate. Furthermore, to account for empirical surface reflectances which require (at least) three degrees of freedom in surface reflectance functions, the algorithm requires four types of receptors. But even if the algorithm should not teach us much about the actual mechanisms of human color perception, the underlying approach is certainly a whetstone to clarify our basic concepts. Maloney's approach particularly shows in a precise mathematical way, how strong the implications are that can be derived from ecological considerations about the 'physical friendliness' of our environment.

\subsubsection{Qualitative Observations on the Dialectic Relationship of Illumination and Object Color}

Plausible as computational approaches of the kind mentioned above are at first sight (provided one restricts attention to appropriate " $\mathrm{semi-ccological}$ " situations, such as a 'Mondrian world'). these approaches have systematic drawbacks from a psychological point of view. The most general objection is that the reduction of color perception to estimating surface reflectances is, from the point of view of perceptual psychology, nearly as misleading as the locally atomistic wavelengthbased perspective. The claim that "the goal of color vision is to recover the invariant spectral reflectance of objects (surfaces)" (Poggio. 1990. p. 147) amounts to a distal variant of the measurement device conception of perception. Though the adaptive coupling of the organism to its environment takes strong advantage of physical regularities of physical reflectances, the claim that the estimation of spectral reflectance functions is a goal of color vision amounts to underestimating constraints derived from its internal 'semantic structure', as it were, and imputes to the visual system a goal that is not consonant with its actual achievements. What is achieved is not an estimation of spectral reflectance functions, but rather an abstractive categorial description of the "color of a perceived object', which is more stable than can be expected on the basis of the local sensory input. i.e., the wavelength composition of the light coming from the object to the eye. In this sense, the percept 'color of an object' seems to be more strongly tied to the spectral reflectance characteristics of the object than to the wavelength composition of the local sensory input. There is. howerer, no color constancy in the strict sense that two locations of the same spectral reflectance "look the 
same' under two different illuminations. Complex scenes rather require a notion of "cquality of color appearances" whose meaning depends on the judgmental task and the observer's 'mode of perception'. This was already stressed by Katz, who also observed that color appearances under chromatic illumination have a peculiar character of a kind that cannot be encountered under normal illumination. "Attempts to establish color appearances within a field of view in qualitatively normal illumination that in all respects are equal to color appearances that can be encountered in fields of view in chromatical illumination, are prone to fail" (Katz, 191 l, p. 274)". The often subtle phenomenal differences in appearance have escaped appreciation in computational perspectives. This is partly due to the fact that computational psychophysicists are often loath to admit any consideration of phenomenological appearance. Conscquently, the construction of illumination independent color codes tends to be divorced from the construction of appropriate appearance codes. Another reason for this situation lies in our lack of a suitable theoretical language for the phenomenal description of the percept associated with the interplay of perceived illumination and perceived objects, since such a description has to deal with aspects of, for instance, vagueness, abstraction and eategorization.

In the classic literature we find many attempts to carcfully describe the phenomenal peculiarities that are characteristic for color appearances under (chromatic) illumination. Helmholtz (1911, Vol. 2, p. 243) described them as "colors that can be seen at the same location of the visual field one behind the other:" Bühler (1922, p. 40) spoke of "locating colors in perceptual space one behind the other" ("Hintereinander von Farborten im Wahrnehmung sraum" "), "colors appear as if they were composed of the actual object color and a coating by

\footnotetext{
"Innerhalb eines qualitativ normal beleuchteten Gesichtsfeldes wird man vergeblich Farbeindrücke herzustellen versuchen, die denen in jeder Bezichung gleichen. welche wir in buntfarbig beleuchteten (iesichtsfeldern antreffen."

"Farben, die in demselben Teil des Gesichtsfeldes vorhanden sind" und wo "cine Farbe durch dic andere hindurch $7 . \mathrm{s}$ sehen ist"
}

the chromatic illumination." Katz (1911, p. 274) noted "the curious lability of colors under chromatic illumination." Similar observation can be found in Hering (e.g., 1888), Fuchs (1923), or Gelb (1929).

Even everyday situations, say a white wall in a room illuminated by a reddish light, can arouse intriguing kinds of impressions in a careful observer:

- we can 'see' both the color of the object ('white' wall) and the color of the illumination (in many cases there is, through shifts of attention, some freedom in how we 'decompose' the sensory input into an 'object color component' and an 'illumination color component')

- the colors of objects in the room are less distinctive and more vague than under "normal illumination' (though we tend to have good access to the "colors of the objects")

the gamut of colors tends to shrink the more the illumination deviates from a white one (which gives rise to the conjecture that the visual system might use something like the variance of Grassmann codes for an assessment of the illumination)

- a white illumination seems to be special in that we cease to have the impression of a separate illumination at all.

Furthermore, a green light, for instance, and an olive-green surface exhibit some phenomenological similarity: Though in principle these two 'worlds' of colour appearances could have been phenomenologically completely divorced from each other, the adaptive requirement of colour constancy necessitates the possibility of at least a partial compensation and continuous transition between the two.

From present-day computational perspectives, phenomenological descriptions like these more or less seem to be merc exercises in phenomenology that do not promise to provide further theoretical insights. However, if one abandons the inappropriate assumption that properties of color coding can completely be understood in terms of, or even be

Farben "erscheinen, als ob sie aus der eigentlichen Objektfarbe und einem daraufliegenden Häutehen aus der farbigen Belcuchtung zusammengescizt scien" 
derived from the goal of recovering spectral reflectances, the question again arises in which way adaptive properties of the internal coding of color can be described more appropriately. Observations like the ones above may then provide strong heuristics about what the actual achievements of the visual system with respect to color perception are and about how the attribute of color is interlocked with spatial aspects that in turn are interrelated with the 'interpretation' of the scenes in terms of 'objects' and 'illumination' (one cannot overemphazise the point stressed by Koffka, 1936, p. 129, that "a general theory of color must at the same time be a general theory of space and form").

\subsection{Center-Surround Configu- rations as Minimal Stimuli for Triggering a Dual Code for 'Object Colors' and 'Illumination Colors'}

The ecological perspective on color perception heuristically starts out from a physical description of the sensory input in terms of complex achievement-related concepts such as 'surface', 'specular highlights', 'shadows', etc. It then attempts to construct complex abstract color codes backwards, as it were, from an appropriate physical description of the perceptual achievements, say color constancy. For instance, one tries to find color codes (considered as functions of the input) that are equal if the reflectances that are part of the physical input description are equivalent (i.e., equal up to multiplication). Approaches like these again amount to succumbing to the physicalistic trap, since they presuppose that the perceptual categories (e.g., of 'light' or 'surface') are constituted by the corresponding physical categories (of physical lights or surfaces). Such an assumption, however, cannot be derived from the cvolutionary requirement of an adaptive coupling of perceptual categories to biologically relevant physical ones. In point of fact, the perceptual categories 'surface colors' vs. 'illumination colors' are not constituted by the corresponding categorics of physics and tied to them in the sense of the latter being necessary and sufficient conditions for the former. Rather they are constituted by a set of biologically relevant features that are specific to physically contingent organism-environment relations.

A proper physical description of these relations should therefore not be couched in the vocabulary of still-to-be-identified perceptual categories. Not much is known today about the internal semantics. as it were, of the visual system, but there are good reasons to assume that basic 'semantic' units of perception are predetermined and tied to certain spatio-temporal characteristics of the incoming energy.

Approaches to deal with the problem of the internal perceptual semantics of organisms were developed by v. Uexküll, v. Frisch, Lorenz, Tinbergen, and, for situations where, like in visual perception, the unit of analysis is not the entire organism but certain (often abstractly idealized) 'mechanisms', by Lashley, Bühler, Brunswik and Barlow, to mention only a few names. Barlow (1961, p. 219) summed up this perspective under the watchword "password hypothesis": "Specific classes of stimuli act as 'releasers' and evoke specific responses; these classes of stimuli are thought of as 'passwords' which have to be distinguished from all other stimuli, and it is suggested that their detection may be the important function of sensory relays."

An exposition of these ethological perspectives as applied to the problem of how elcmentary perceptual categories come about is beyond the scope of this paper and will be given elsewhere. In the present context only some heuristic intuitions will be addressed as to the general question whether there are critical minimal stimulus characteristics that already trigger attempts of the visual system to 'interpret' them in terms of certain perceptual categories. Are the perceptual categories of 'illumination color' and 'object color' internally constituted not by an extensive set of properties of corresponding physical entities, but rather by a few 'representative' ones? If so, these physical characteristics could be instantiated by an otherwise highly reduced stimulus, which then would suffice to trigger an internal perecptual structure whose complexity far exceeds the complexity of 
the triggering stimulus. The initial mapping of sensory inputs on internal codes is, on this view, innately specified in terms of an environmental semantics".

According to such a perspective, the dialectic relationship of illumination and object is mirrored in a perceptual bi-segmentation of the visual field (corresponding to the fovea-cxtrafovea segmentation of the retina). The main function of the surrounding field is - besides detection of motion and optical flow, and orientation in space - to estimate the illumination, and not to identify objects of which this surrounding field is composed. The problem of approximate color constancy is, on this view, misrepresented by current computational accounts. If color is part of the format of representing the environment, i.e., a property of the organization of the perception instinct that couples our perceptuo-motorial system as a whole to its environment, processes underlying phenomena of approximate color constancy are not necessarily coupled to certain invariant characteristics of physical objects, to wit spectral reflectances, but rather are part of the way the system is organized. Consequently these complex internal structures can be triggered by appropriate but highly unecological stimuli (though in evolutionary history physical properties of natural spectral reflectances played a crucial role for the development of these propertics of internal organization). Once triggered they create mandatory 'interpretations' in terms of a dual code for 'illumination color' and "object color".

An interesting candidate for such classes of stimuli are center-surround type configurations, traditionally associated with mechanisms of early color coding (like sensitivity control and opponent processing) and exhibiting phenomena like simultaneous eontrast. Already Helmholtz observed that under natural conditions simultaneous contrast rarely occurs (a phenomenon that in modern terms can be related to the important computational goal of achicving scene invariance of color designators, i.e. the color of an object should not vary with the color of neighboring objects). There seems to be something special about the geometrical configuration of small and sharply demarcated infields in large surrounds. The phenomena observed in these situations led Hering and later, in a more pronounced way, Jaensch, Gelb, Bühler, Kardos and Müller to assign a special status to center-surround stimuli and to favor a functional interpretation of the corresponding results in terms of 'higher-level' achievements. For instance K. Bühler (1922, p. 131) interpreted the phenomenon of simultaneous contrast in such situations as a degenerate marginal phenomenon attesting to the visual system's capability of preserving colors under changes of illumination.

With respect to different aspects there is strong empirical and theoretical evidence that suggests regarding center-surround type stimuli as 'minimal' stimuli for triggering mechanisms of the visual system that provide basic constituents for the perceptual categories of 'illumination color' and 'object color' and their interplay. In the next two sections I shall sketch some of the experimental indications in support of such a triggering of elementary perceptual categories by center-surround situations.

\subsubsection{Laminar Segmentation and a Dual Code for 'Object Color' and 'Illumination Color'}

In the Octant Model, $\phi(\mathrm{S})$ can be regarded as a measure of some level set by $<\mathrm{A}$, $\mathrm{S}>$ with which the inficld $A$ is to be compared in such a way that $\phi(\mathrm{A})-\phi(\mathrm{S})$ is processed and for each component subjected to a surround-dependent multiplicative transformation $\rho_{\mathrm{i}}[\phi(\mathrm{S})]$. According to this model, the corresponding three-dimensional code for the color appearance of the infield is described formally by a contrast operator which involves taking differences of primary codes and applying contrast-dependent multiplicative transformations in each of the three components.

The idea that the dialectic relationship of object and medium, and of 'object color' and 'illumination color' is a fundamental part of the structural form of our visual world, together with an ethology-inspired perspective that considers center-surround configurations as kinds of sign stimuli for an 'object under chromatic illumination' sheds new light on the specific way - as captured in the 
incrementally linear color code of the Octant Model - in which in center-surround configurations 'large-disc information' and 'small-dise information' are segregated by the visual system. From this perspective, this segregation mirrors processes that are related to the segregation of object and illumination information. If the centersurround configurations contain physico-geometrical properties that already trigger the visual system's 'interpretation' in terms of small, sharply demarcated objects under chromatic illumination, one should be able to observe, under suitable conditions, phenomena like those described in section 12.5.2 also in center-surround configurations.

Indeed, in our color-cancellation experiments we found phenomena, where, again in Bühler's words, "colors appear as if they were composed of the actual object color and a coating by the chromatic illumination" and where in perceptual space one color is located behind the other.

The following example of an experiment may serve to illustrate such phenomena: We used under Maxwellian-viewing conditions - using the apparatus shown in Figure 12.1 - a red surround $\left(\lambda=649 \mathrm{~nm}, 150 \mathrm{td}, 8-10^{\circ}\right)$, where the $2^{\circ}$-infield was composed of a mixture of monochromatic light $\left(\Delta \mathrm{R}_{649} \oplus \Delta \mathrm{G}_{546}\right)$. The subjects had to perform (by a two-alternative forced choice double-random staircase) reddish/greenish-judgments and to make a setting where the infield appears neither reddish nor greenish. While for most values of

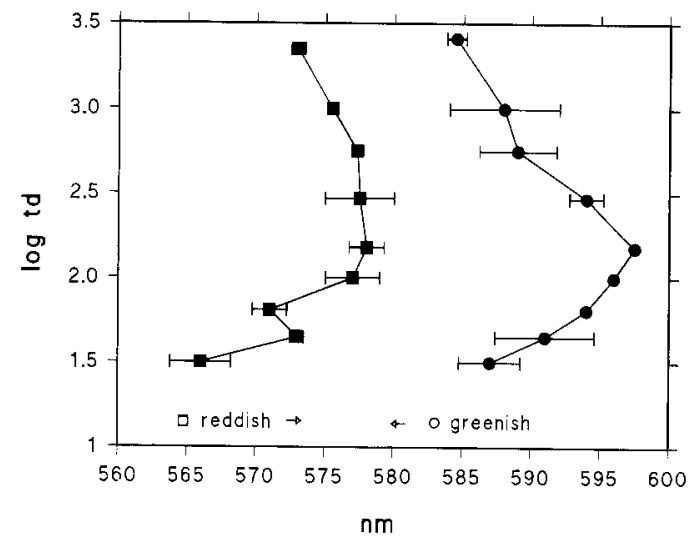

Fig. 12.4: Range of reddish/greenish appcarence of infield on red background of $150 \mathrm{td}$. stimulus parameters subjects were able to satisfy this judgmental criterion (and made settings that are consonant with predictions derived from the Octant Model), they reported for certain stimulus parameters (large surrounds, contrasts not too high, predominantly in the decremental domain) seeing a reddish and a greenish component simultaneously.

Figure 12.4 shows for a typical experiment the range of dominant wavelengths of the infield (for different intensities) within which a reddish and greenish color appearance (with a, in Katz's words, "curious lability of colors") is seen simultaneously (the left curve indicates the lower bound of reddish appearances of the infield, the right curve the upper bound of greenish appearances, in between are infields that appear reddish and greenish simultaneously).

Subjects were not able to completely cancel the amount of redness at the position of the infield by increasing the green component of the infield. There seem to be two layers between which there is no complete trade-off. I consider this observation as a further indication that center-surround

'Illumination color' laver

'Object color' laver

Retinal intensity profil

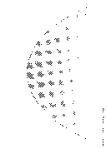

Fig. 12.5: Laminar segmentation of the retinal intensity profil. 
situations already trigger a laminar segmentation of the retinal intensity profile into an 'object color" component and an "illumination color' component as metaphorically indicated by Figure 12.5 - and give rise to a dual color code for these two components.

\subsubsection{Segregation of 'Object Color' and 'Illumination Color' in Minimal Seurat-type Configurations}

So far I only referred to center-surround configurations in which the surround corresponds to an area that is spatially uniform, i.e., homogeneous in terms of spectral energy distributions. The central heuristic underlying the approach proposed here is that such homogeneous center-surround configurations can be regarded as minimal stimuli for triggering a dual code for 'object colors' and 'illumination colors". Though the above phenomenon of laminar segmentation already can be interpreted as some indication along this line, in order to establish a more convincing case in favor of this conjecture, one has to establish a "continuous path". as it were, that connects this minimal situation via increasingly more complex ones with semi-ecological ones, like Mondrian-type situalions or three-dimensional seenes.

It is not the physico-geometrical property of being a center-surround configuration, but rather the perceptual feature of a certain figure-ground segmentation that triggers basic mechanisms subserving 'color constancy' that is of importance here. Already Rubin (1921, p. 56) observed that transformations in the direction of color constancy are stronger if a certain area is perceived as figure than if it is perceived as ground." The homogeneous center-surround configuration can be considered as the prototypical situation for triggering a figure-ground segmentation, according to what

daß diejenigen zentralen Faktoren, durch welche die auf einer farbigen Beleuchtung beruhende Verändertng in der Farbe der Dinge kompensiert werden. stärker wirksam sind an dem Felde, das als Figur, als an dem, welches als Grund hervortritt."
Rubin (1921, p. 79) called a "fundamental law" ("Fundamentalregel"): in situations where a homogeneous field of small size is surrounded by a much larger homogeneous field, there is a predominant tendency to perceive the enclosed smaller ficld as figure.

In a series of experiments in collaboration with Johannes Andres we attempted to bridge the gap from homogeneous center-surround configurations to Mondrian configuration by a sequence of configurations (presented on a CRT screen) of the following kind. For each homogeneous surround (characterized by the corresponding Grassmann coordinates) a family of spatially inhomogenous surrounds, which have the same space-average Grassmann coordinates (globally, and within several smaller annular regions of increasing distance from the infield), is constructed by varying the following parameters:

- bandwidth of spatial variation of spectral inhomogencities

- spatial inhomogeneities achieved by varying the degrees of modulation along the luminance axis - spatial inhomogeneities achieved by varying the degrees of modulation along the red-green axis The geometrical layout of spatial variations of the surround is given by a random structure of overlapping circles (with occluding intersections) of a certain diameter (defining bandwidth of spatial variation). The infield has the same size as in the previous experiment with homogeneous centersurround configurations and consists of a mixture of red and green which has to be brought to a redgreen equilibrium.

For very small diameters of the circles of the surround and if both luminance and chromatic modulations are employed, the stimulus configuration is reminiscent of the Neo-Impressionistic style of painting (see Fig. 1.20 of chapter 1). Because of this, I refer to these stimuli as Seurattype configurations. Increasing the diameter leads to patterns that resemble, say, a piece of fruit against a background of leaves, or a flower against a background of grass or soil. For circles with very large diameters a Mondrian-type of configuration is obtained. Using these kinds of stimulus configurations we can systematically investigate continuous transitions of complexity between center-sur- 


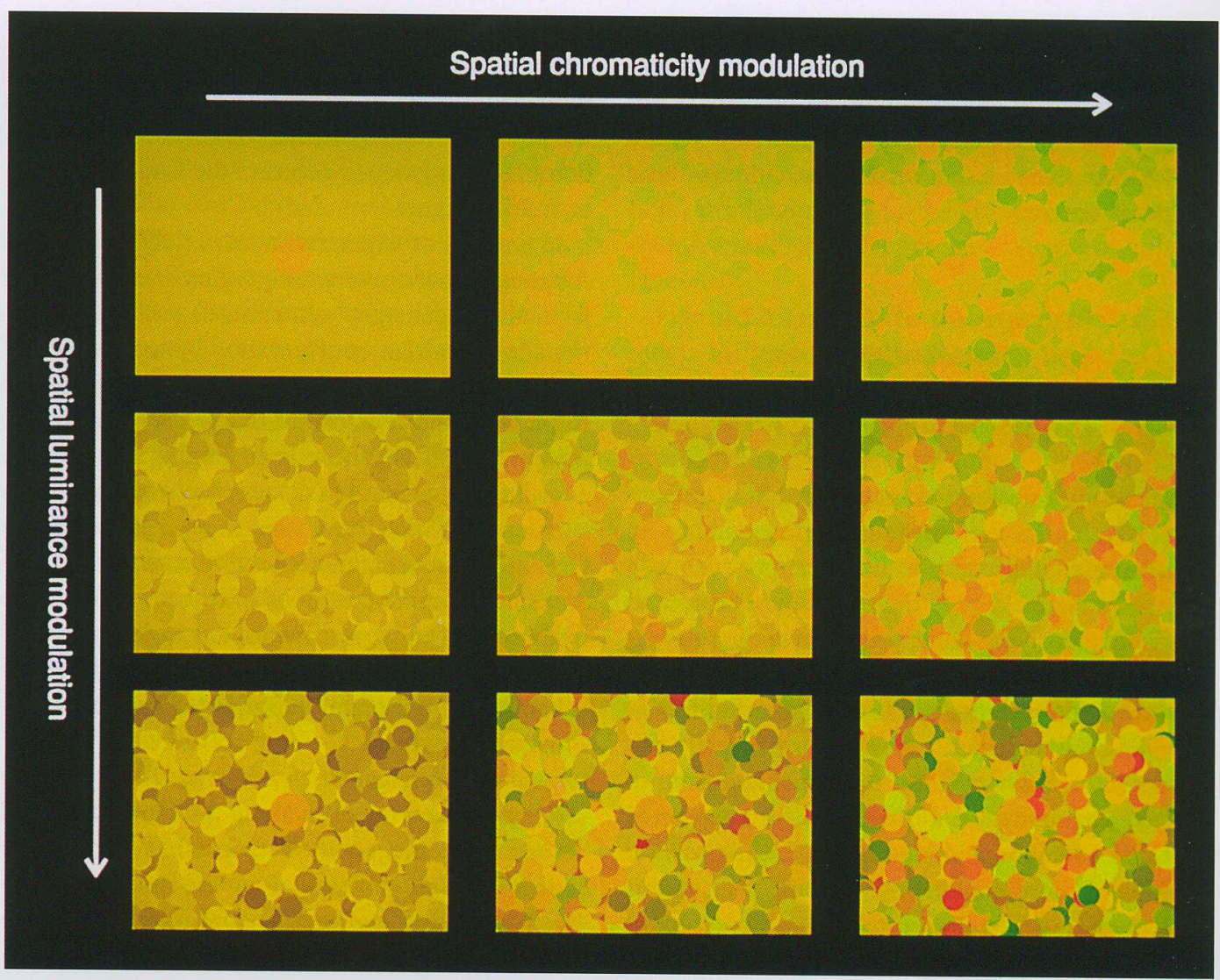

Fig. 12.6: Seurat configurations of intermediate bandwidth of spatial variation of the surround and of the same spatially-averaged chromaticities, with spatial luminance modulation increasing on the vertical axis, and chromaticity modulation increasing on the horizontal axis.

round type stimuli with a homogeneous surround and Mondrian-type configurations and thereby study those physical properties of such configurations that trigger an interpretation in terms of the elementary perceptual categories of 'object color' and 'illumination color'.

For an intermediate bandwidth of spatial variation of the surround, Figure 12.6 shows typical configurations with spatial luminance modulation increasing on the vertical axis, and chromaticity modulation increasing on the horizontal axis. For all $\cdots$ displays in this figure the space-average Grassmann codes of the surrounds are identical to the ones of the homogeneous surround in the display in the upper left.

According to traditional adaptational models all these stimuli are functionally equivalent, i.e., are expected to exhibit the same effect on the unique yellow settings at the location of the infield. A typical example of a simple adaptation model of a space-averaged von Kries-type sensitivity control assumes that $\Phi(\mathrm{A}, \mathrm{S})$ can be understood in terms of some linear 'pooling mechanism' $\varphi_{\mathrm{i}}(\mathrm{S})=\Sigma_{\mathrm{j}} \mathrm{w}_{\mathrm{ji}} \varphi_{\mathrm{i}}\left(\mathrm{S}\left(\mathrm{y}_{\mathrm{j}}\right)\right)$, where $\mathrm{S}\left(\mathrm{y}_{\mathrm{j}}\right)$ denotes the spectral energy distributions of the surround at the location $\mathrm{y}_{\mathrm{j}}$, and $\mathrm{w}_{\mathrm{j} i} \in[0,1]$ are location-dependent weights (possibly decreasing with distance to the infield), summing up to 1 . While our data clearly reveal that in our Seurat-type stimuli, surrounds with equal space-averaged Grassmann coordinates grossly violate any functional equivalence with respect to the unique yellow settings of the infield, 
they suggest an interpretation in terms of a triggering of elementary perceptual categories related to 'object color' and 'illumination color'.

Since a detailed report of our experiments will be published separately, I shall only briefly mention some qualitative results that are of interest in the present context. If a unique yellow test spot, e.g., with a dominant wavelength of $575 \mathrm{~nm}$, is surrounded by a homogeneous reddish surround (with a dominant wavelength of, say, $596 \mathrm{~nm}$ ), the dominant wavelength for the infield needs to be shifted towards longer wavelengths, e.g., to $585 \mathrm{~nm}$, in order for a red-green equilibrium to be preserved. We now kept the infield at the same luminance as the surround $\left(\mathrm{L}=9 \mathrm{~cd} / \mathrm{m}^{2}\right)$ and spatially modulated the surround along the red-green axis only, along the luminance axis only and simultaneously along both axes, while keeping the spatial average fixed.

For an isochromatic surround (Fig. 12.7 left), i.e., no red-green variation and spatial luminance variation only, the red-green equilibrium settings showed a stronger shift towards longer wavelength than the ones for the corresponding homogeneous surround. A reduced variance of color codes in the surround seems to increase the visual system's propensity to interpret the configuration as an illuminated scene. For the case of an isoluminant surround (Fig. 12.7 right) with strong spatial redgreen modulation only, the opposite effect showed up, i.e. the unique yellow settings strongly tended towards the ones of a dark surround or a spaceaveraged achromatic surround. A qualitatively similar result for a red background field with sparse white and green dots has been obtained by Jenness \& Shevell (1995). The finding for isoluminant surrounds can be related to the functional goal of achieving approximate scene invariance for the color codes of the infield. (The difference between surround configurations of isoluminant and isochromatic patches is more pronounced for reddish surrounds than for greenish ones, as is to be expected from considerations about natural illumination variations.)

These experimental phenomena can be accommodated by the general perspective outlined above according to which the surround-dependent change in appearance of an infield in a center-surround configuration is not to be understood as an elementary re-coding of channels by a simple surround-dependent gain control, but in fact mirrors the triggering of a much more complex mechanism for establishing a dual code for 'object color' and 'illumination color'. The case of isoluminant chromatic spatial modulation results in a proximal stimulus pattern that is highly improbable to result from surfaces under chromatic illumination; it is a non-generic view, as it were. Such a configuration fails to trigger a proper dual code for illumination and object colors and thus does not activate any illuminance correction (this is analoguous to the observation that a non-generic view of a Necker cube fails to trigger a 3D-interpretation).

The results of our experiments support, in my view, the idea that all color processing is cast into
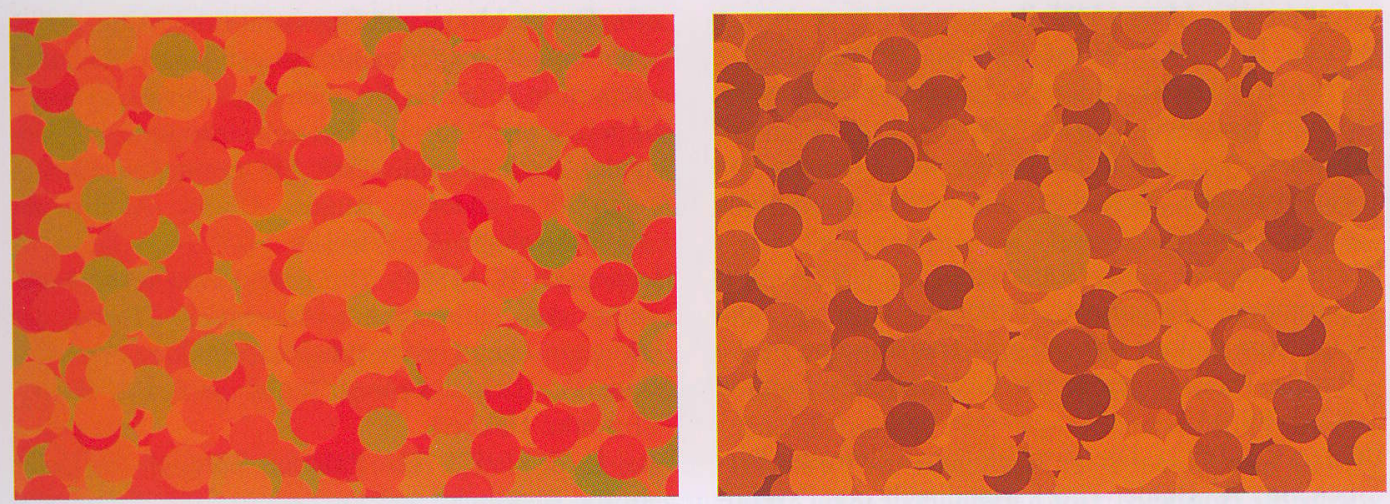

Fig. 12.7: Isochromatic (left) and isoluminant (right) Seurat configuration with same spatially averaged chromaticities. 
the format of innate semantic perceptual categories of 'object color' and 'illumination color', which in turn are intimately interwoven with representations for elementary perceptual categories for the representation of surfaces, form and space. According to this view, perceptual achievements such as the segregation of object and illuminant color are brought forth by the very organization of the internal representation of color rather than being computationally derived from properties of sensory inputs. This reflects the difference between two different metaphors in perceptual theory: triggering vs. computation.

\section{Acknowledgements}

I should like to thank Johannes Andres, Don MacLeod and Larry Maloney for their valuable comments on an earlier draft of this paper.

\section{References}

Ahn, S. J. and MacLeod, D. I. A. (1993). LinkSpecific Adaptation in the Luminance and Chromatic Channels. Vision Research 33, 2271-2286.

Alpern, M., Kitahara, K., and Krantz, D. H. (1983). Perception of Colour in Unilateral Tritanopia. Journal of Physiology 335, 683-697.

Barlow, II. (1961). Possible Principles Underlying the Coding of Sensory Messages. In: W. Rosenblith (Ed.), Sensory communication (pp. 217-234). Cambridge, Mass.: MIT Press.

Barlow, H. (1982). What Causes Trichromacy? A Theoretical Analysis Using Comb-Filtered Spectra, Vision Research 22, 635-643.

Brückner, A. (1927). Zur Frage der Eichung von Farbsystemen. Zeitschrift für Sinnes physiologie 58, 322-362.

Buchsbaum, G. and Gottschalk, A. (1993). Trichromacy, Opponent Colours Coding and Optimum Colour Information Transmission in the Retina. Proceedings of the Royal Society London $B 220,89-113$.

Bühler, K. (1922). Die Erschcinungsweisen der Farben. In: K. Bühler (Ed.), Handbuch der Psychologie. I. Teil. Die Struktur der Wahrnchmungen (pp. 1 201). Jena: Fischer.
Fechner, G. T. (1840). Über die subjective Nachbilder und Nebenbilder. Poggendorff's Annalen der Physik und Chemie 50. 193 221; 427470.

Forsyth, D. A. (1990). Colour Constancy. In: A. Blake and T. Troscianko (Eds.). AI and the Eyo (pp. 201-227). Chichester: Wiley.

Foster, D. H. and Nascimento. S. M. C. (1994). Relational Colour Constancy from Invariant ConeExcitation Ratios. Procedings of the Royal Society London $B 257,115-121$.

Frumkina, R. M. (1984). Colour, Meaning, and Similarity. Aspects of Psycholinguistic Analysis (Цвет, смысл, сходствоa), (in Russ.) Moscow: Nauka.

Fuchs, W. (1923). Experimentelle Untersuchungen über das simultane Hintereinandersehen aul derselben Sehrichtung. Zeitschrift tür Psychologic 91. 145235.

Gelb, A. (1929). Dic 'Farbenkonstanz' der Sehdinge. In: A. Bethe, G. v. Bergmann. (i. Fmbden, and A. Ellinger (Eds.). Handbuch der normalen und pathologischen Physiologic. Bd. 12. 1. Hälfte. Receptionsorgane II (pp. 594-678). Berlin: Springer.

Grassmann, H. (1853). Zur Theoric der Farbmischung. Poggendorff's Annalen der Physik und Chemie 89, 69-84.

Helmholtz, H. v. (1911). Handbuch der physiologischen Optik (3.Ed., 3 Vol., Fds. W. Nagel. A. Gullstrand, J. v. Kries). Hamburg: VoR.

Hering, E. (1888). Ueber die Theorie des simultanen Contrastes von Helmholtz. IV. Mittheilung. Dic subjective 'Trennung des Lichtes in zwei complementäre Portionen.' Pflüger's Archiv für die gesanmte Physiologie des Menschen und der Thiere 4.3. 121.

Hering, E. (1920). Grundzüge der Lehre rom Lichtsinn. Berlin: Springer.

Heyer, D. (1996). The Relation of Contrast Coding in the Octant Model and Opponent Processing: A thicoretical and Experimental Investigation. Teclnical report, Institute für Psychologic, Universität Kiel.

Hippel, A. v. (1880). Ein Fall von einseitiger, congenitaler Roth-Grünblindheit bei normalem Farben. sinn des anderen Auges. Gräfes Arehiv für Ophtalmologic 26, 176-186.

Hochegger, R. (1884). Die geschichtliche Fntwicklung des Farbensinnes. Inmsbruck: Verlag der Wagner'schen Universitätsbuchhandlung.

Irwin, E. (1974). Colour Terms in (ireek Poctry. Toronto: Hakkert.

Ives, H. E. (1912). The Relation Between the Color of the Illuminant and the Color of the Illuminated Object. Transactions of Illuminating Engincering Society $7.62-72$. 
Jenness, J. W. and Shevell, S. K. (1995). Color Appearance with Sparse Chromatic Context. Vision Research 35, 797-805.

Jansch, E. (1914). Über Grundfragen der Farbenpsychologie. Bericht über den VI. Kongreß für experimentelle Psychologie (pp. 45-56). Leipzig.

Jameson, D. and Hurvich, L. M. (1972). Color Adaptation: Sensitivity, Contrast, After-Images. In: D. Jameson and L. M. Hurvich (Eds.). Handbook of Sensory Physiology. Vol. VII/4. Visual Psychoplysics (pp. 568 881). Heidelberg: Springer.

Kardos. L. (1934). Ding und Schatten. Eine experimentelle Untersuchung über die Grundlagen des Farbensehens. Lcipzig: Barth.

Katz.. D. (1911). Die Erscheinungsweisen der Farben und ihre Beeinflussung durch die individuelle Erfahrung. Leipzig: Barth.

Koflka. K. (1936). On Problems of Colour-Perception. Acta Psychologica /, 129-134.

Krauskopf, J.. Williams, D. R., and Heeley, D. W. (1982). Cardinal Directions in Color Spacc. Vision Rescarch 20, 11231131.

Krics. I. \. (1882). Die Gesichtsempfindungen und ihre Analysc. Leipzig: Veit.

Macl.cod. D. I. A. (1978). Visual Sensitivity. Annual Review of Psychology 29,613-645.

MacLcod. D. I. A. (1986). Receptoral Constraints on Colour Appearance. In: D. Ottoson and S. Zeki (lids.), Central and Peripheral Mechanisms of Colour Vision (pp. 103-116). London: Macmillan. MacLeod, D.I.A. and Lennic, P. (1976). Red-Green Blindness Confined to One Eye. Vision Research 10.691-702.

Maloney, L. T. (1985). Computational Approaches to Color Constancy. Stanford University: Technical Report 198501 .

Maloncy, L. T. (1992). Color Constancy and Color Perception: The Linear Models Framework. In: D. I. Meyer and S. Kornblum (Eds.), Attention and Performance XIV: Synergies in Experimental Psychology, Artificial Intelligence, and Cognitive Neuroscience (pp. 59-78). Cambridge, Mass.: MIT Press.

Matusfeld. R. (1993). Methodologische Grundlagen und Probleme der Psychophysik. In: Th. Herrmann and W. Tack (Hrsg.) Methodische Grundlagen der Psychologic. Enzyklopädie der Psychologic, Bereich B, Scric I, Bd. 1, (pp. 137-198). Göttingen: Hogrete.

Mausfeld. R. (1996). "Wär" nicht das Auge sonnenhaft ..." Goethes Farbenlehre nur cine Poesie des Chromatischen oder Beitrag zu einer naturwisienschafilichen Psychologie? ZiF Report 2/1996,
Zentrum für Interdisziplinäre Forschung der Universität Bielefeld.

Mausfeld, R. and Niederée, R. (1991). Scalar Invariance in Opponent Colour Theory and the Discounting the Background Principle. In: J. P. Doignon and J.-C. Falmagne (Eds.), Mathematical Psychology: Current Developments (pp. 55-69). New York: Springer.

Mausfeld, R. and Niederce, R. (1992). On IncrementDecrement Differences in Multiplicative Gain Control. In: Advances in Color Vision Technical Digest, Optical Socicty of America, Washington, D.C., Vol. 4, 170-171

Mausfeld, R. and Niederéc, R. (1993). Inquiries into Relational Concepts of Colour Based on an Incremental Principle of Colour Coding for Minimal Relational Stimuli, Perception 22. 427-462.

Marty, A. (1879). Die Frage nach der geschichtlichen Entwicklung des Farbensinnes. Wien.

Neitz, J., Neitz, M., and Jacobs, (3. H. (1993). More Than Threc Different Cone Pigments among People with Normal Color Vision. Vision Research $33,117-122$.

Niederée, R. (1996). Continuity considerations in colour perception: Why already in centresurround stimuli colour appearances cannot be coded threedimensionally. Technical report, Institute für Psychologie, Universität Kicl.

Niederće, R. and Mausfeld, R. (1996). IncrementDecrement Asymmetry in Dichoptic Matching with Haploscopically Superimposed Displays. Vision Research 37, 613-615.

Poggio, T. (1990). Vision: The 'Other' Face of AI. In: K. A. Mohyeldin Said, W. H. Newton-Smith, R. Viale and K. V. Wilkes (Eds.), Modelling the Mind (pp. 139-154). Oxford: Clarendon Press.

Ratliff, F. (1976). On the Psychophysical Bases of Universal Color Terms. Proceedings of the Americal Philosophical Society 120, 311-330.

Rubin, E. (1921). Visuell wahrgenommene Figuren. Kopenhagen: Gyldendalske Boghandel.

Schrödinger, E. (1920). Grundlinicn ciner Theorie der Farbenmetrik im Tagessehen. Annalen der Physik 63, 397-426, 427-456, 481-520.

Shepard, R. N. (1992). The Perceptual Organization of Colors: An Adaptation to Regularities of the Terrestrial World? In: J. H. Barkow, L. Cosmides and J. Toby (Eds.), The Adapted Mind. Evolutionary Psychology and the Gencration of Culture (pp. 495-532). New York: Oxford University Press.

Shepard, R. N. (1994). Perceptual-Cognitive Uni- 
versals as Reflections of the World. Psychonomic Bulletin and Review 1, 2-28.

Stumpf, C. (1917). Die Attribute der Gesichtsempfindungen. Abhandlungen der königlich preussischen Akademie der Wissenschaften. Philosophisch-historische Klasse, 8. Berlin: Verlag der Königl. Akademie der Wissenschaften.

Suppes, P., Krantz, D. H., Luce, R. D., and Tversky, A. (1989). Foundations of Measurement, Vol. II. New York: Academic Press.

Walraven, J. (1976) Discounting the Background The Missing Link in the Explanation of Chromatic Induction, Vision Research 16, 289-295.

Walraven, J., Enroth-Cugell, C., Hood, D. C., MacLeod, D. I. A., and Schnapf, J. L. (1990). The Control of Visual Sensitivity: Receptoral and Postreceptoral Processes. In: L. Spillmann and J. S. Werner (Eds.), Visual Perception. The
Neurophysiological Foundations (pp. 53-101) Academic press: San Dicgo.

Walraven, J. and Valeton, I. M. (1984). Visual Adaptation and Response Saturation. In A. J. Van Doorn, W. A. Van de Grind and J. J. Koenderink (Eds.), Limits in perception. Utrecht: VNU Science Press.

West, G. and Brill, M. H. (1982). Necessary and Sufficient Conditions for von Kries Chromatic Adaptation to Give Colour Constancy. Journal of Mathematical Biology 15, 249-258.

Waetzold, W. (1909). Das theoretische und praktische Problem der Farbbenennung. Zeitschrift für $\ddot{\Lambda}$ sthetik und allgemeine Kunstwissenschaft 4, 349--399. Wyszecki, G., and Stiles, W. S. (1982). Color Science. Concepts and Methods, Quantitative Data and Formulae. (2nd Ed.). New York: Wiley. 